\title{
Experimental Validation of Direct Predictive Control of Variable Speed Wind Energy Conversion System Based on DFIG
}

\author{
Said Chikha ${ }^{1 *}$, Kamel Barra $^{2}$, Abd Allatif Reama ${ }^{3}$ \\ ${ }^{1}$ Faculty of Technology, University of El Oued, 39000 El Oued, P.O.B. 789, Algeria \\ ${ }^{2}$ Electrical Engineering and Automatic Laboratory (LGEA), University of Oum El Bouaghi, 04000 Oum El Bouaghi, P.O.B. 358, Algeria \\ ${ }^{3}$ Embedded System Department (ESIEE), 93162 Noisy-le-Grand Cedex, P.O.B. 99, France \\ * Corresponding author, e-mail: chikha-said@univ-eloued.dz
}

Received: 03 July 2020, Accepted: 08 December 2021, Published online: 21 February 2022

\begin{abstract}
The paper presents the design and the implementation of a direct predictive control of a variable speed wind energy conversion system. The conversion chain uses a Doubly Fed Induction Generator DFIG whereas the control method is based on a Finite States Model Predictive Control FS-MPC. The proposed control method selects the optimal switching state of the two levels back to back power converter that minimizes the cost function, where this optimal voltage vector is applied on the output of the power converter in next sampling time. The proposed predictive control strategy uses only one sample time prediction and it is intuitive since it is very simple for implementation. In order to adjust the measured rotor currents to track their references, the error between orthogonal rotor current components predictions to their computed values used to select the optimal vector and applied on the power converter in rotor side CSR in next sampling time. On other side, based on the error between the active and reactive power prediction and their references of the electrical grid, the predictive algorithm control of the gird side converter CSG kept the Dc-link voltage constant and guarantee that the whole system functioning with unity power factor. The experimental results confirm the advantages of using this structure for wind energy conversion system and the effectiveness of the proposed control strategy.
\end{abstract}

Keywords

variable speed wind energy conversion system, DFIG, finite set model predictive control, cost function

\section{Introduction}

The global consumption of electricity observed over the last few decades is strongly linked to the development of industry, transport and communications. Fossil fuels, such as petroleum, coal and natural gas, are the most widely used fuels for the production of electric power today because of low production costs but lead to a massive release of gas pollutants. Thus, electricity production from fossil fuels is responsible for $40 \%$ of global $\mathrm{CO}_{2}$ emissions. On the other hand, their rate of regeneration is extremely slow on a human scale. This will lead, in the short term, to a nonzero risk of depletion of these resources. In this context, most developed countries have focused on clean, non-polluting renewable sources of energy. Among the various technologies developed, the turbine occupies a considerable place. In 2021, the $93 \mathrm{GW}$ of new installations brings total cumulative installations up to $743 \mathrm{GW}$ in the world [1].

Electric power conversion systems using a Doubly Fed Induction Generator (DFIG) are the most popular configurations due to its advantages in the medium and high power such as: a variable speed operating range and operating capacity in the four quadrants $[2,3]$. In general, the stator winding of DFIG is directly connected to the grid providing electric power with constant voltage and frequency, while the rotor winding is connected to the grid via a tow levels back-to-back converter (two cascaded converters connected with a direct current DC link). The Rotor Side Converter RSC controls the direct and quadrature rotor currents components of the generator while the Grid Side Converter GSC controls the DC link voltage and ensures operation of large power factor. As the rotor speed is fluctuating, the electric power of the rotor is reversible depending on whether the machine operates in either sub synchronous mode or super synchronous mode. Other advantages of DFIG machines can be cited, such as the adaptability of the power factor, better efficiency and the ability to control the reactive power without 
capacitive support. Also, they allow a significant reduction of the power converters size and cost since the size of the converters is related to the speed variation range, typically around $+-30 \%$ of the synchronous speed. Note that the main advantage of the WECS based DFIG machine is the perfect decoupling between active and reactive power control by controlling rotor currents [4].

Among the two last decades, several control strategies for WECSs based DFIG have been reported in specialist literature starting from the basic idea that control does significantly improve all aspects of WECS and the most widely used techniques may be classified within the Field Oriented Control (FOC) techniques [5, 6], the Direct Torque Control (DTC) [7-9], and Direct Self Control (DSC) [10].

Recently; Finite-States Model Predictive Control (FS-MPC) appears as a complete and accurate approach to control power converters due to its fast dynamic response, no need for linear controllers in inner loops, no need for modulator (as in PWM or SVM modulation), completely different approach compared to PWM and SVM modulations, extremely simple, good performance and can be implemented with standard commercial microprocessors [11]. The method uses the model of the system to predict for one step ahead prediction the behavior of the variables for each switching state. For the selection of the appropriate switching state to be applied to the system a quality function must be defined. The cost function is then evaluated for the predicted values on each sampling interval and the optimal switching state that minimizes the quality function is selected to apply during the next sampling interval $[12,13]$.

In this paper, we will extend the application and implementation of FS-MPC to WECS based on DFIG since the most papers in this field are mostly related to classic control methods. The superiority of FS-MPC over conventional control will be confirmed by simulation and experiment results.

\section{System modeling}

Several variable-speed WECS configurations are being widely used in [14]. The schematic diagram of a DFIG based wind energy generation system studied in this paper is shown in Fig. 1 where the rotor winding is connected to the utility grid via two power converters. The Rotor Side Converter RSC controls the direct and quadrature components of the rotor currents while the Grid Side Converter GSC controls the DC link voltage and ensures operation of large power factor [15].

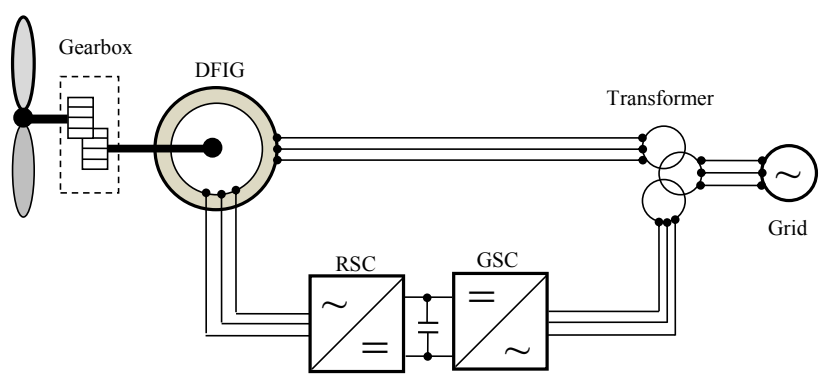

Fig. 1 Schematic diagram of a DFIG based wind energy generation system

\subsection{DFIG modeling}

The equations that describe a doubly fed induction generator in a $d q$ reference frame where different parameters of the machine appear in a continue form are identical to those of a squirrel cage induction generator; the only exception is that the rotor winding is not short-circuited. We assume balanced voltages and non-ground connection points. Two orthogonal axes are defined, the $d$ and $q$ axis. The rotor voltages are given by Eq. (1) [16]:

$\left\{\begin{array}{l}V_{d r}=R_{r} i_{d r}+\frac{d \psi_{d r}}{d t}-w_{s l} \psi_{q r} \\ V_{q r}=R_{r} i_{q r}+\frac{d \psi_{q r}}{d t}+w_{s l} \psi_{d r}\end{array}\right.$.

In order to obtain a decoupled control of stator activereactive powers, the DFIG model requires all quantities to be expressed under stator flux orientation concept and assuming that the stator resistance is small when compared to the stator reactance for medium and high power size machine, the stator flux can be computed as $[17,18]$ :

$\left\{\begin{array}{l}\psi_{d s}=\psi_{s} \\ \psi_{q s}=0\end{array} \rightarrow \psi_{s} \approx \frac{V_{s}}{\omega_{s}}\right.$.

Then the torque is simplified into:

$C_{e m}=p \psi_{d s} i_{q s}=-p \frac{M}{L_{s}} \psi_{d s} i_{q r}$.

The stator active-reactive powers expressions are:

$\left\{\begin{array}{c}P_{s}=V_{d s} i_{d s}+V_{q s} i_{q s}=-V_{s} \frac{M}{L_{s}} i_{q r} \\ Q_{s}=V_{d s} i_{q s}=\frac{V_{s}^{2}}{w_{s} L_{s}}-\frac{V_{s} M}{L_{s}} i_{d r}\end{array}\right.$.

The dynamics of the rotor current components can be expressed then from relations (Eqs. (2), (3) and (4)) by: 


$$
\left\{\begin{array}{c}
V_{d r}=R_{r} i_{d r}+\sigma L_{r} \frac{d i_{d r}}{d t}-s w_{s} \sigma L_{r} i_{q r} \\
V_{q r}=R_{r} i_{q r}+\sigma L_{r} \frac{d i_{q r}}{d t}+s w_{s} \sigma L_{r} i_{d r}+s \frac{M V_{s}}{L_{s}}
\end{array} .\right.
$$

\subsection{Modeling of the grid network and DC-link voltage}

In order to decouple and further simplify the grid-side converter system linked to the electrical network through an RL filter, the synchronous angular speed is typically chosen equal to the angular speed of the network voltage, and the axis $d$ of the rotating frame is aligned with the grid voltage vector:

$v_{d g}=v_{g} ; v_{q g}=0$,

the $d q$ current components of the electrical network voltages are given by:

$$
\begin{gathered}
\frac{d i_{d g}}{d t}=\frac{1}{L_{g}}\left(v_{d p}-R_{g} i_{d g}+\omega_{s} L_{g} i_{q g}-v_{d g}\right) \\
\frac{d i_{q g}}{d t}=\frac{1}{L_{g}}\left(v_{q p}-R_{g} i_{q g}-w_{s} L_{g} i_{d g}\right)
\end{gathered},
$$

where $v_{d p}$ and $v_{q p}$ denote the output voltage components of the converter; $v_{d g}$ and $v_{q g}$ represent the grid voltage components; and $i_{d g}$ and $i_{q g}$ are the phase current components in $d q$ reference frame.

The orientation of the grid voltage not only simplifies the filter current equations, but also reduces the calculations of active and reactive grid power. Here, instantaneous active and reactive power inputs are given by:

$$
\left\{\begin{array}{c}
P_{g}=v_{g} i_{d g} \\
Q_{g}=-v_{g} i_{q g}
\end{array} .\right.
$$

The two power converters of the wind power conversion system (GSC and RSC) are interconnected via a DC bus so allows power transfer between the rotor of the DFIG and the electrical grid [19], the DC-link capacitor voltage can be expressed in terms of the DC-link capacitor current as follows:

$V_{d c}=\frac{1}{C} \int i c . d t$,

where the $d c$ current $i_{c}$ in super synchronous mode given by (the transfer of the electrical power from the rotor to the electrical grid:

$i_{c}=I_{R S C}-I_{G S C}$, and DC current $i_{c}$ in sub synchronous mode given by the transfer of the electrical power from the electrical grid to the rotor:

$i_{c}=I_{G S C}-I_{R S C}$.

The $\mathrm{C}$ is the DC-link capacitor, $I_{R S C}$ is the output current of the RSC and $I_{R S C}$ is the output current of the GSC.

\subsection{Two level voltage source inverter model}

To describe the inverter output voltages, the concept of complex space vector is applied. For a two-levels voltage source inverter feeding a symmetrical three-phase grid connected system given in Fig. 2, each leg is composed of two by-directional switches $\left(S_{i 1}, S_{i 2} i=a, b, c\right)$ where $a, b, c$ three phases. The switching states $S$ determined by gating signals are given in vector form as follows [20]:

$S=\frac{2}{3}\left(S_{a}+a S_{b}+a^{2} S_{c}\right)$,

where $a=e^{j 2 \pi / 3} \cdot S_{i}$ takes the value of 0 if $S_{i 1}$ is off and $S_{i 2}$ is on, $S_{i}$ takes the value of 1 if $S_{i 1}$ is on and $S_{i 2}$ is off.

The output voltage space vectors of the inverter are:

$V=\frac{2}{3}\left(v_{a N}+a v_{b N}+a^{2} v_{c N}\right)$.

$\left(v_{a N}, v_{b N}, v_{c N}\right)$ are the phase to neutral $(N)$ voltages.

As it is well known, there are eight possible voltage vectors that the inverter can apply to the grid terminals. By using these switching functions the grid space voltage vector can be expressed as:

$V\left(S_{a}, S_{b}, S_{c}\right)=\sqrt{\frac{2}{3}} V_{d c}\left(S_{a}+S_{b} e^{j 2 \pi / 3}+S_{c} e^{j 4 \pi / 3}\right)$,

where $V_{d c}$ is the Dc-link voltage.

According to the combinations of switching modes, the space vectors $V_{7}(0,0,0)$ and $V_{8}(1,1,1)$ are the space zero

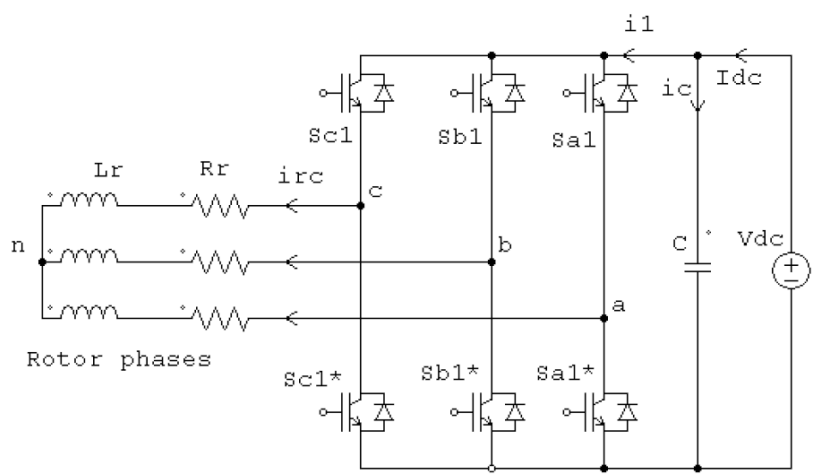

Fig. 2 Tow level Neutral Point Clamped inverter topology (2L-NPC) 


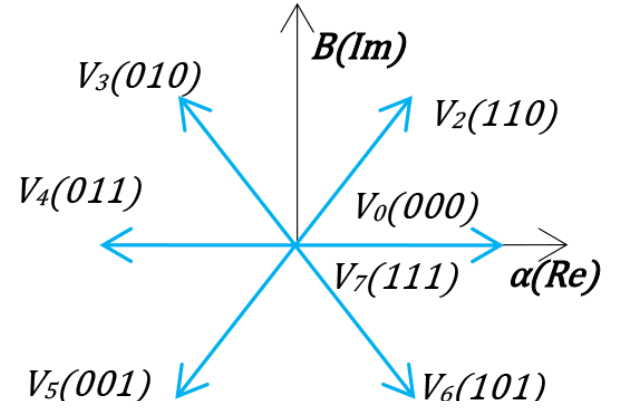

Fig. 3 Representation of different voltage vectors of a two-levels voltage inverter

voltage vectors and the others are the space nonzero active voltage vectors as shown in Fig. 3.

Also, the inverter output voltage is related to DC link voltage by:

$V=V_{d c} S$.

The inverter output voltage vector is kept constant during the switching period, so the inverter current and, hence, the grid currents can be controlled by choosing the appropriate voltage vector.

\section{Predictive Control of the back to back converter}

\subsection{Control of the rotor side converter}

\subsubsection{Predictive model of the rotor current}

For a two-level voltage source inverter or rectifier, the finite set of states of the switches $S_{1}, \ldots, S_{6}$ contains only six different voltage active vectors and two null voltage vectors [21], the dynamics of the rotor current components can be expressed from relations Eq. (5) by :

$$
\left\{\begin{array}{c}
\frac{d i_{d r}}{d t}=\frac{1}{\sigma L_{r}}\left(V_{d r}-r_{r} i_{d r}+s w_{s} \sigma L_{r} i_{q r}\right) \\
\frac{d i_{q r}}{d t}=\frac{1}{\sigma L_{r}}\left(V_{q r}-r_{r} i_{q r}-s w_{s} \sigma L_{r} i_{d r}-s \frac{M V_{s}}{L_{s}}\right)
\end{array}\right.
$$

where $V_{d q_{-} r}$ are the output voltage space vectors generated by the inverter.

By approximating the derivative $\frac{d i_{d q_{-} r}}{d t}$ in Eq. (16) for a sampling time $T$ by:

$$
\frac{d i_{d q_{-} r}}{d t}=\frac{i_{d q_{-r}}(k+1)-i_{d q_{-} r}(k)}{T} .
$$

Prediction of rotor current components can be made for one step ahead prediction as:

$$
\left\{\begin{array}{c}
i_{d r}(k+1)=\frac{T}{\sigma L_{r}}\left(V_{d r}(k)-r_{r} i_{d r(k)}+s w_{s} \sigma L_{r} i_{q r}(k)\right)+i_{d r}(k) \\
i_{q r}(k+1)=\frac{T}{\sigma L_{r}}\left(V_{q r}(k)-r_{r} i_{q r}(k)-s w_{s} \sigma L_{r} i_{d r}(k)-s \frac{M V_{s}}{L_{s}}\right)+i_{q r}(k)
\end{array} .\right.
$$

\subsubsection{Minimization of a cost function}

The cost function $C$ summarizes the desired behavior of the inverter. The control objective is to get high performance in term of rapid and precise dynamic current control response by using a quadratic cost function that minimizes the error between reference currents to their computed values. The predictions on rotor currents are used to evaluate the impact of every voltage vector on the WECS. The cost function is formulated as [22-24]:

$C_{R S C[7]}=\left|i_{d r}^{*}-i_{d r}^{k+1}\right|+\left|i_{q r}^{*}-i_{q r}^{k+1}\right|$.

The flow chart of the proposed predictive control is given by Fig. 4, where for each rotor voltage vector the cost function $C$ is evaluated and the voltage vector that minimizes the cost function is then applied during the next sampling period according to the receding horizon control [22].

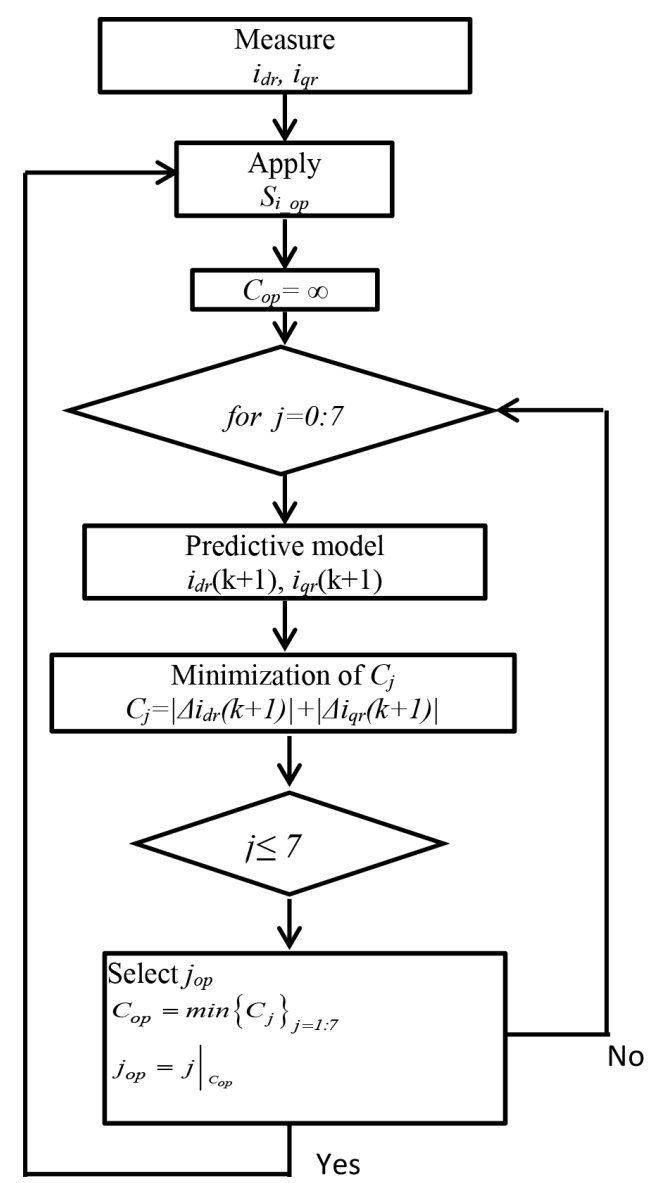

Fig. 4 Flow chart of the predictive algorithm for the RSC 


\subsection{Control of the grid side converter}

\subsubsection{Predictive model of the grid power}

By applying the Euler approximation method described above to Eq. (7), we obtain the following discrete model:

$$
\begin{aligned}
& \begin{aligned}
i_{d g}(k+1) & =\frac{T_{s}}{L_{g}}\left(v_{d p}(k)-R_{g} i_{d g}(k)+\omega_{s} L_{g} i_{q g}(k)\right. \\
& \left.-v_{d g}(k)\right)+i_{d g}(k), \\
i_{q g}(k+1) & =\frac{T_{s}}{L_{g}}\left(v_{q p}(k)-R_{g} i_{q g}(k)-\omega_{s} L_{g} i_{d g}(k)\right) \\
& +i_{q g}(k),
\end{aligned} \\
& \left\{\begin{array}{c}
P_{g}(k+1)=v_{g}(k) * i_{d g}(k+1) \\
Q_{g}(k+1)=-v_{g}(k) * i_{q g}(k+1)
\end{array}\right.
\end{aligned}
$$

\subsubsection{Minimization of cost function}

The objective of the grid side converter GSC control is to regulate the DC bus voltage and controlling the active and reactive power passing through it. The power factor can be set to one simply by imposing a reactive power reference equal to zero. In order to assure this objective, the error between the active/reactive power references and the active/reactive power predicted components is chosen to represent the cost function and given by [25]:

$$
C_{G S C[7]}=\left|P_{g}^{*}-P_{g}^{k+1}\right|+\left|Q_{g}^{*}-Q_{g}^{k+1}\right| .
$$

\section{Control strategy}

Several control algorithms of the WECS have been reported recently through the literature [4, 26-28], whether for a wind system feeding an isolated load, or the network. The configuration of the present work is given by Fig. 5 and Fig. 6; where the rotor of the DFIG is connected to the grid via a back to back power converter and a RL filter assuming that $+/-30 \%$ of the DFIG nominal power is exchanged with the grid whereas the rest of this power is directly generated by the stator to the grid. The Maximum Power Point Tracker MPPT controller is used to track closely the maximum power point of the wind turbine (turbine rotor works closely on the Optimal Regime Characteristic ORC [29, 30]. In this work don't studying the MPPT controller.

The global control structure of the studied WECS using back to back based on two level source voltage converters is given by Figs. 5 and 6. Fig. 5 illustrates the principal work of the model predictive control to control the active and reactive powers of the rotor of DFIG fed by the 2L-NPC inverter. Fig. 6 shows how the grid side converter GSC controls the DC-link voltage and ensures the unity power factor. Technique control is based on model predictive control.

\subsection{Control of DFIG}

Generally, the field oriented control (FOC) concept of the DFIG is based on stator active-reactive power control, however this solution is suitable only when the machine operates in normal regime, but when the grid is affected by

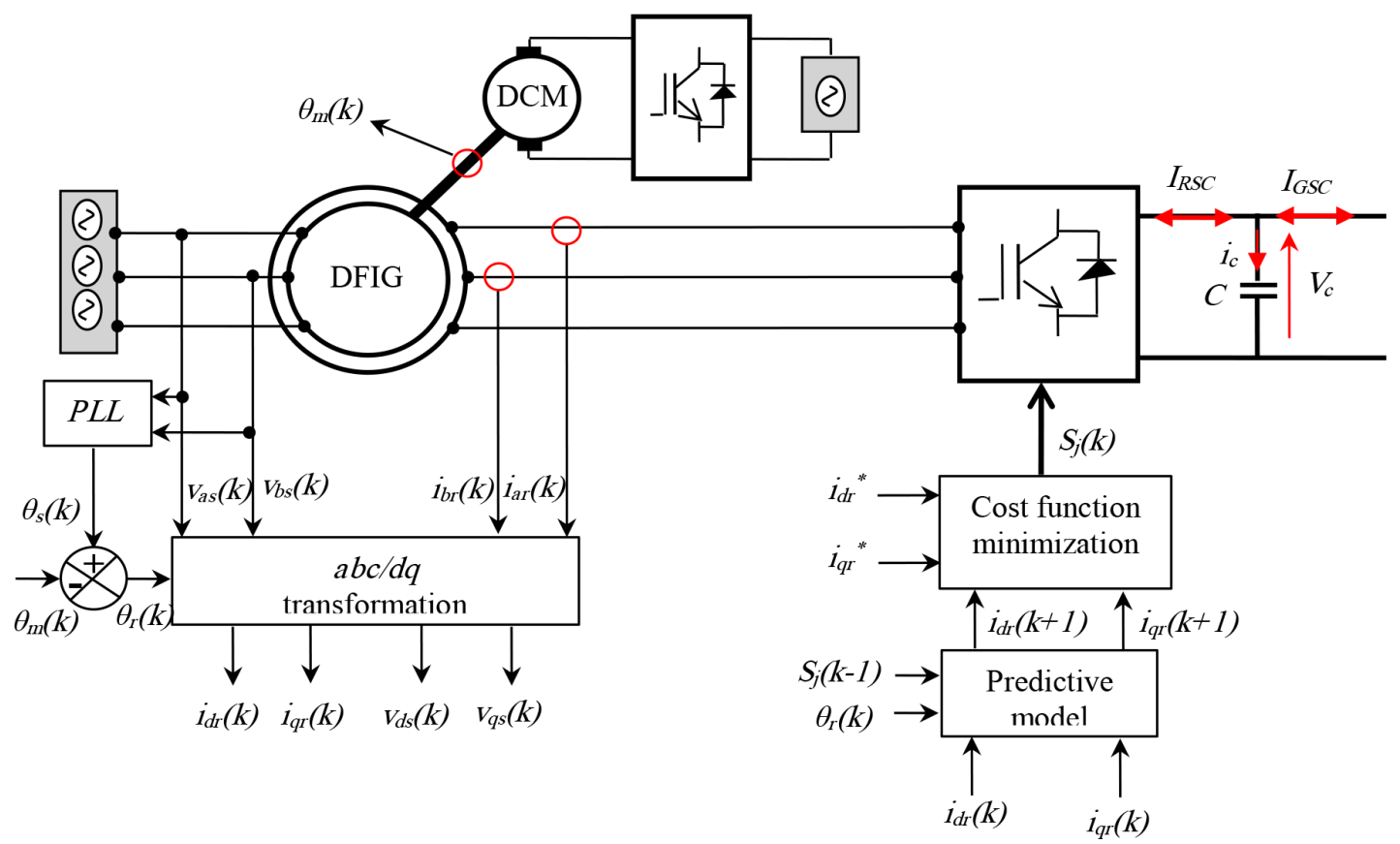

Fig. 5 Model predictive control for rotor side converter 


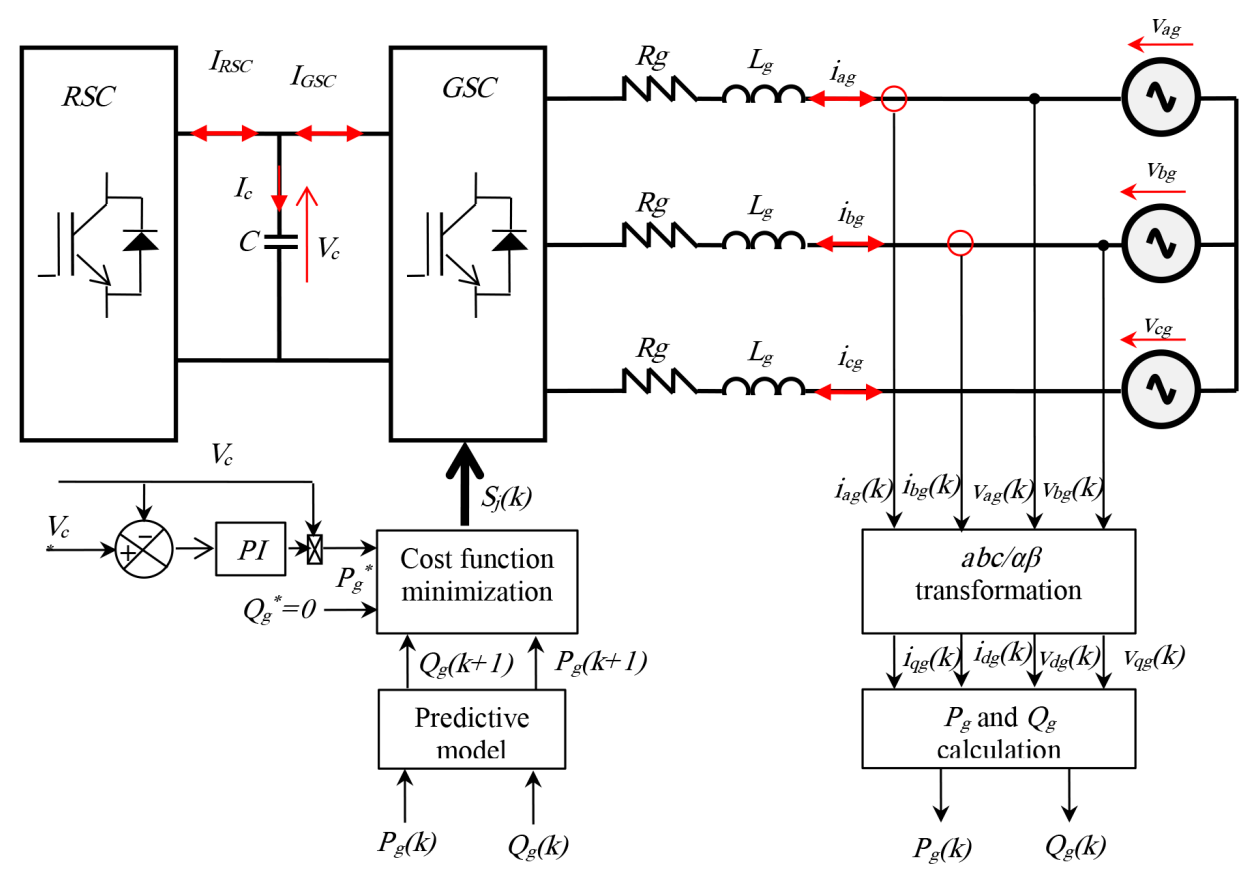

Fig. 6 Model predictive control for a grid side converter

disturbances and faults which is not considered in this study, the measure of stator powers is not appropriate, so the rotor currents are chosen to be directly controlled [4, 26-28].

The rotor currents references can be expressed by:

$i_{q r}^{*}=-\frac{L_{s}}{p M \psi_{s}} C_{e m}^{*}$,

$i_{d r}^{*}=\frac{\psi_{s}}{M}-\frac{L_{s}}{M V_{s}} Q_{s}^{*}$

The stator reactive power $Q_{s}^{*}$ is set to 0 , then the new value of the reference direct rotor current given as follows:

$i_{d r}^{*}=\frac{\psi_{s}}{M}=\frac{\mathrm{V}_{s}}{M \mathrm{w}_{s}}$.

The reference for the stator active power Ps* is then given as:

$$
P_{s}^{*}=\frac{\omega_{s}}{p} \cdot C_{e m}^{*}
$$

\subsection{Control of the power flow side the electrical grid}

The main goal of the grid side converter control is to keep the dc-link voltage constant and to achieve a desired reactive power reference. In normal operation, the power flowing through the grid and rotor side converters is balanced, that is, $P_{r}$ is equal to $P_{g}$, so the DC-link voltage is constant [31]. A PI regulator used to control the dynamic response of the DC link voltage, the output of the PI regulator is multiplying by a DC link voltage to obtain the DC link power $P_{c_{-} r e f}$. The DC bus voltage regulation loop is shown in Fig. 7.

$$
P_{c_{-} r e f}=i_{c_{-} r e f} \cdot V_{d c}
$$

The power appearing in the rotor circuit corresponds to the output power of the DC-link voltage added to the output power of the network (hyper synchronous operation):

$P_{r}=P_{g}+P_{d c_{-} r e f}$.

The active power reference transiting the grid side converter $P_{g_{-} r e f}$ is obtained by subtracting the power $P_{c_{-} \text {ref }}$ of the active power appearing in the rotor of the DFIG $P_{r}$ (hyper-synchronous operation) [32]:

$$
P_{g_{-} r e f}=P_{r}-P_{d c_{r e f}} \text {. }
$$

\section{Experimental implementation and validation}

\subsection{Experimental setup}

The experimental validation of the power wind conversion system was performed on an experimental test rig at reduced power (DFIG and DC-motor with $3 \mathrm{KW}$ ), which is shown in Fig. 8 with the parameters as indicated in Table 1 in the Appendix.

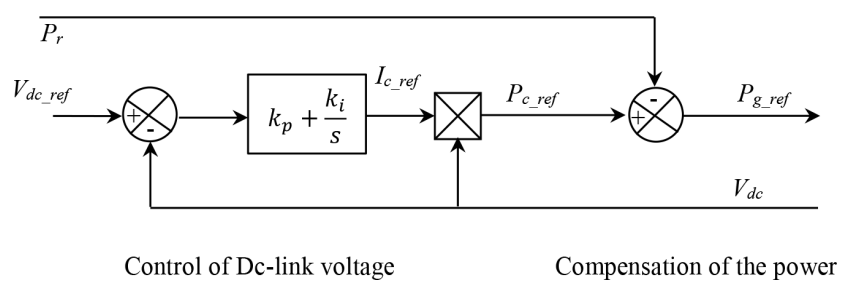

Fig. 7 DC-link voltage controller 


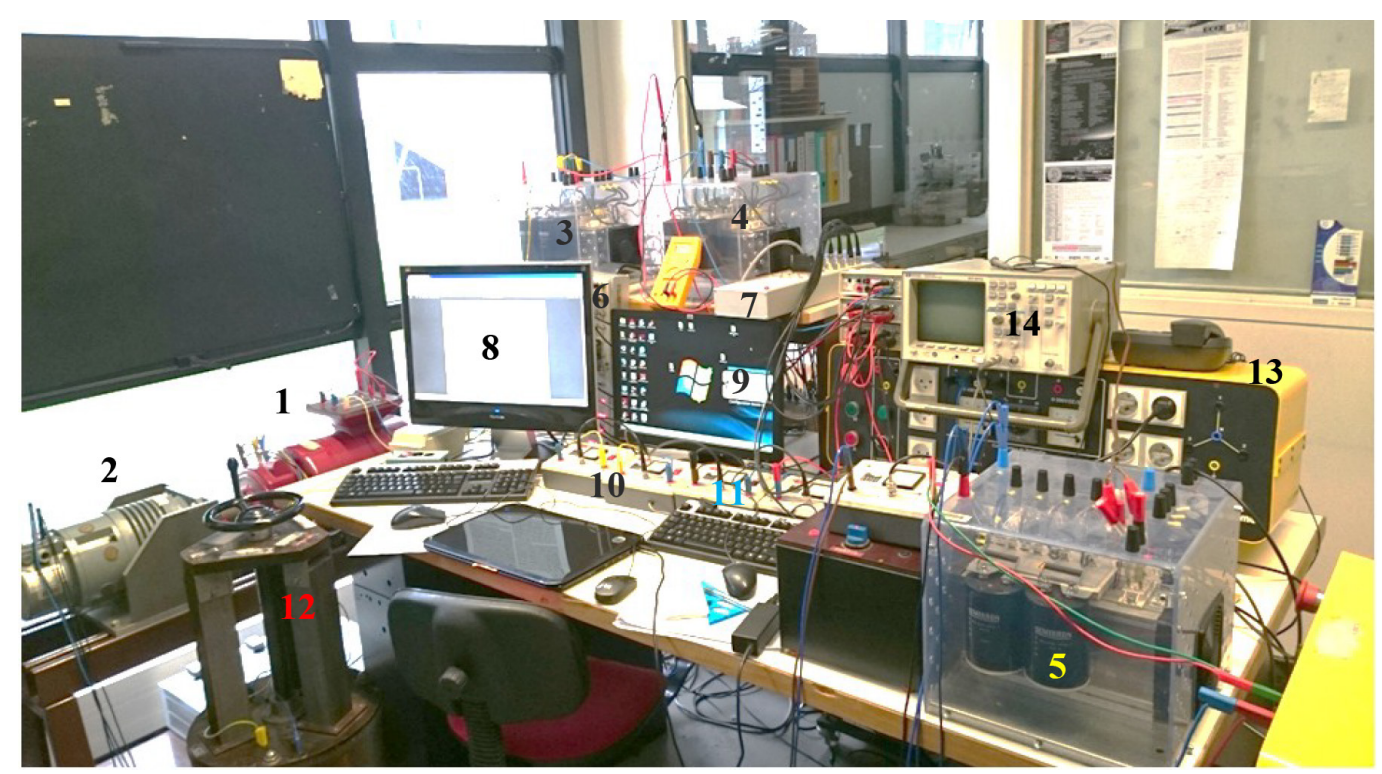

Fig. 8 Photograph of experimental system (1): DFIG, (2): Dc-motor, (3): RSG (two level semikron inverter), (4): GSC (two level semikron inverter),

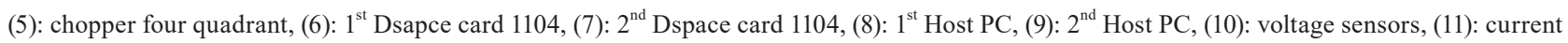
sensors, (12): L filter, (13): 3-phase grid, (14) oscilloscope

The predictive control algorithm has been implemented using a two host PCs running with MATLAB-Simulink 2012a software through Real-Time Interface (RTI). The back-to-back converter between the rotor of the DFIG and the electrical grid contains a two Semikron power converters (inverter or rectifier corresponding the power flow) separate by capacitance bank with $2200 u f$. Each of them controlled separately by two TI TMS320F240 DSPs cards from Texas Instrument. An interface board is used between the dSPACE card and IGBT gate drivers for adapting the interface output signals of the dSPACE TTL $(0 / 5 \mathrm{~V})$ with the logic levels of the input signals of the SKHI 22 driver $(0 / 15 \mathrm{~V})$. Measuring the position of the rotor of the DFIG is performed using an encoder incremental placed on the shaft of the generator. The grid voltage, the Dc-link voltage, the continue current of the DC-motor, the stator currents and the rotor currents are measured with LEM transducers. The inductance of $32 \mathrm{mH}$ is inserted between the rotor of the DFIG and the RSG for smoothing the rotor currents. To feed the DFIG we used the transformer with one input of $220 \mathrm{~V}$ and two outputs with $220 \mathrm{~V}$ for stator and $127 \mathrm{~V}$ for rotor. In order to fix the speed of the DC-Motor at desired value we used the chopper four quadrants, where the rotor of the DFIG coupled directly to a DC machine. The schematic diagram is shown in Fig. 9.

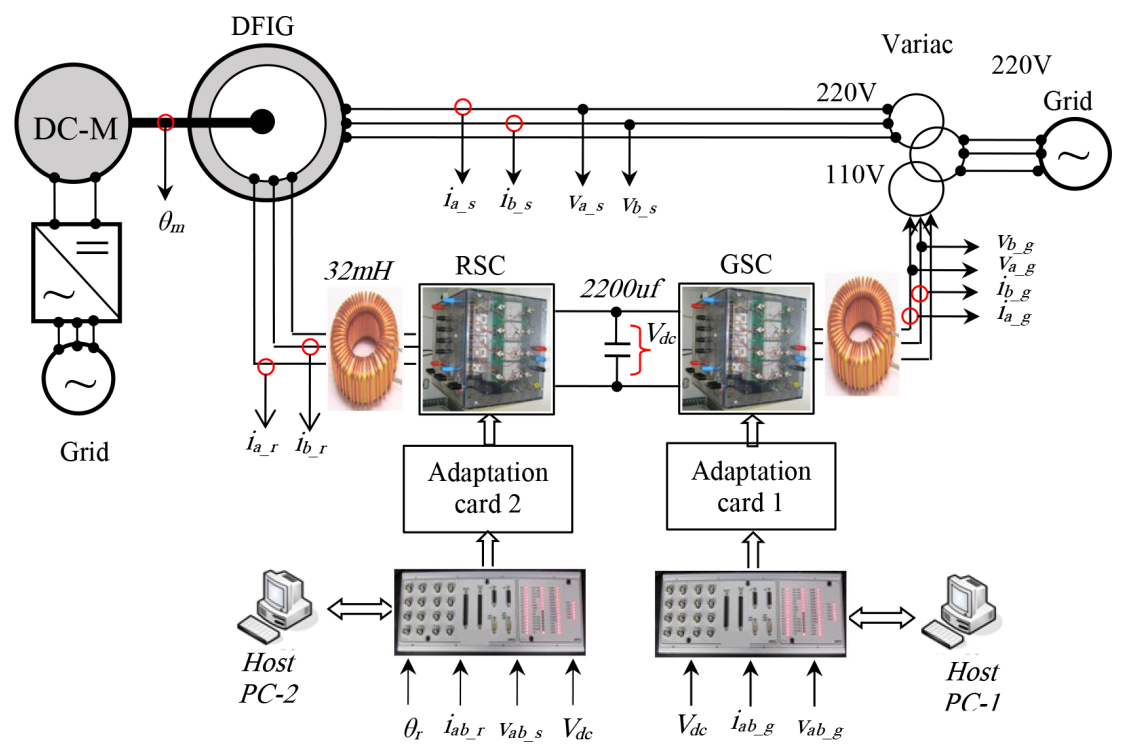

Fig. 9 Schematic diagram of the experimental system 


\subsection{Simulation results}

The proposed predictive control of the studied WECS given by Fig. 5 is tested in Matlab/simulink environment with a sampling time of $90 \mu \mathrm{s}$, considering a DFIG of $3 \mathrm{KW}$ for reduced generation system whose parameters are given in the Appendix. One-step prediction horizon is considered in all the simulation tests. The results are presented in order to show the performance, the speed time response, and the accurate of the tracking reference. The simulations divide in two-parts GSC and RSC simulation.

\subsubsection{GSC results}

Fig. 10 shows the DC link voltage. As it can be seen, after a short transient time $(<0.2 \mathrm{~s})$, is regulated at its reference value $(220 \mathrm{~V})$. The ripple of this DC voltage is less than $2 \mathrm{~V}$. At $1.25 \mathrm{~s}$ the Fig. 10 presents test, which was response to the step change of DC-link voltage reference value from
$220 \mathrm{~V}$ to $250 \mathrm{~V}$, where the DC link voltage response needs just $0.055 \mathrm{~s}$ to achieve a new reference $(250 \mathrm{~V})$.

The grid reactive power tracks to its reference with fast dynamics. The decoupled control for active and reactive powers (thus for $\mathrm{d}$ and $\mathrm{q}$-axis currents, respectively) has been achieved as demonstrated in Fig. 11 and Fig. 12.

Fig. 13 shows the electrical network current, which is in phase with the electrical network voltage. And this compatibility we obtained from the effectiveness of the control technique and forcing it to follow the desired reference.

\subsubsection{RSC results}

In this section, we find the results of the rotor side converter controlling the DFIG. In order to shows the performance of the control algorithm we made several tests (varying in $d$ or $q$ reference current component or the speed generator like hypo synchronous mode to hyper synchronous mode).

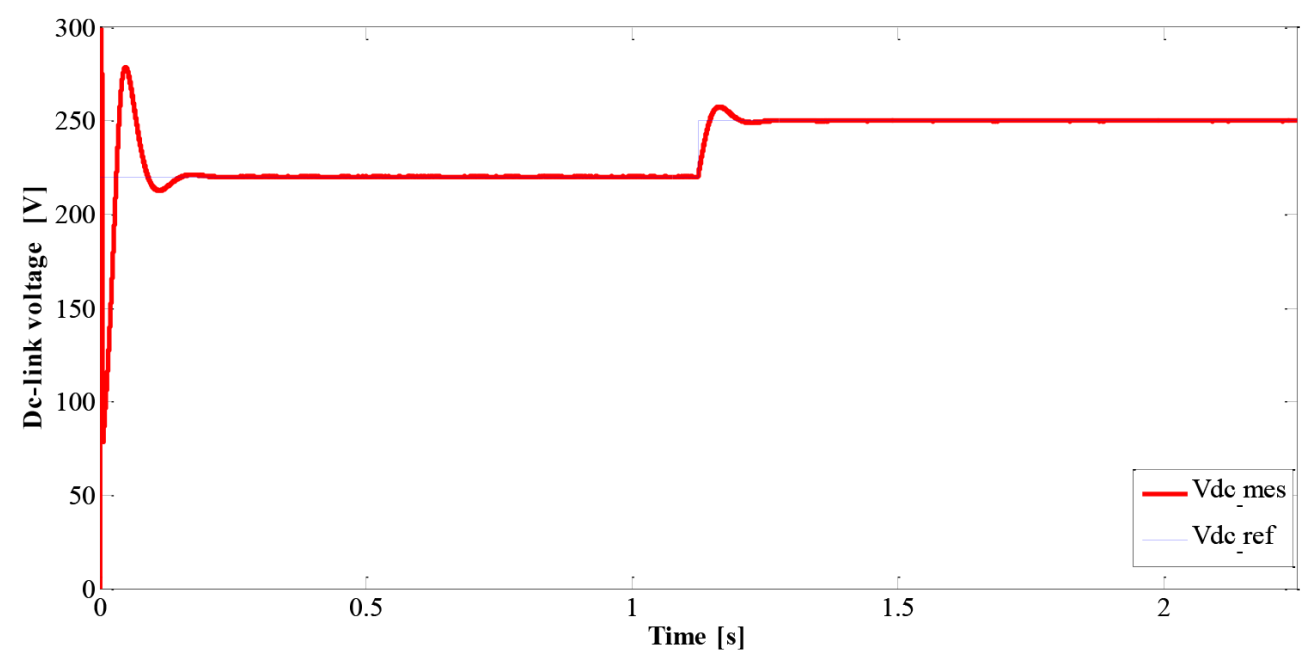

(a)

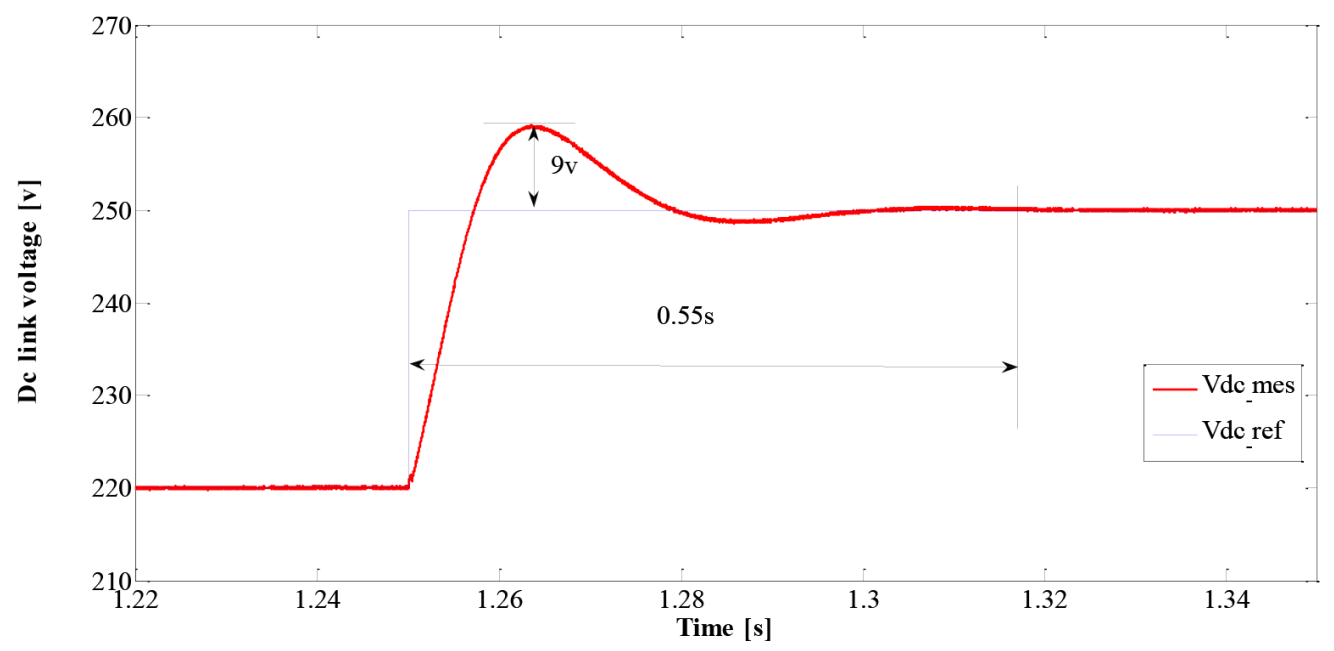

(b)

Fig. 10 a) DC-link voltage; b) Zoom of the dynamic response of DC-link voltage at $1.25 \mathrm{~s}$ 


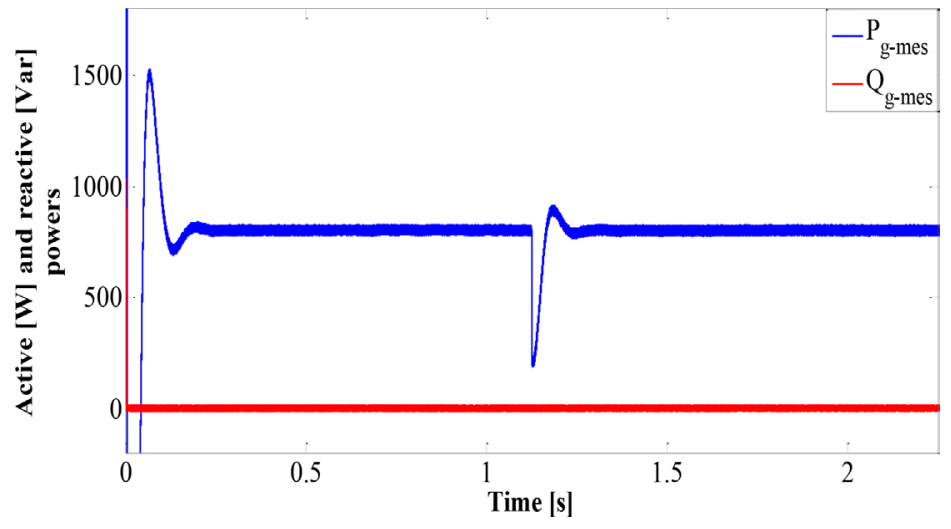

Fig. 11 Active and reactive powers

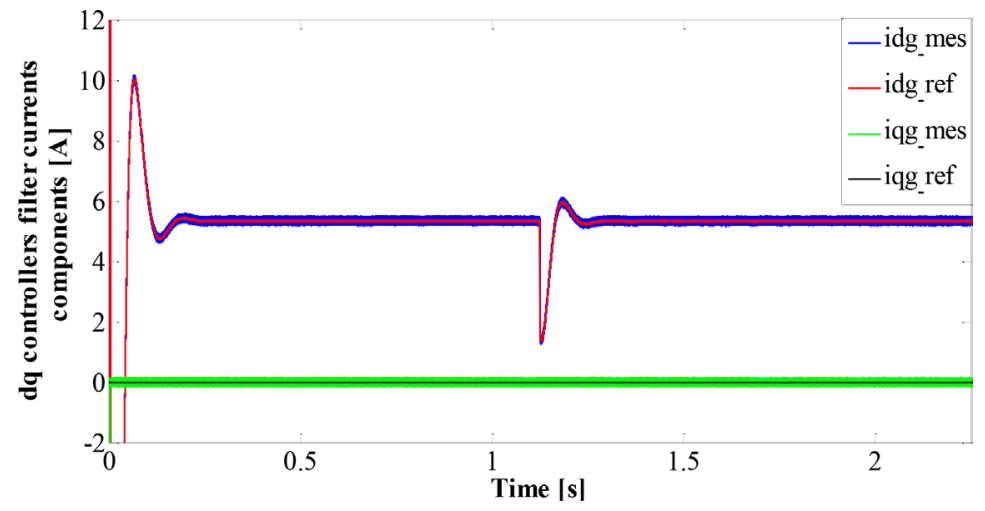

Fig. $12 d q$ controlled filter components

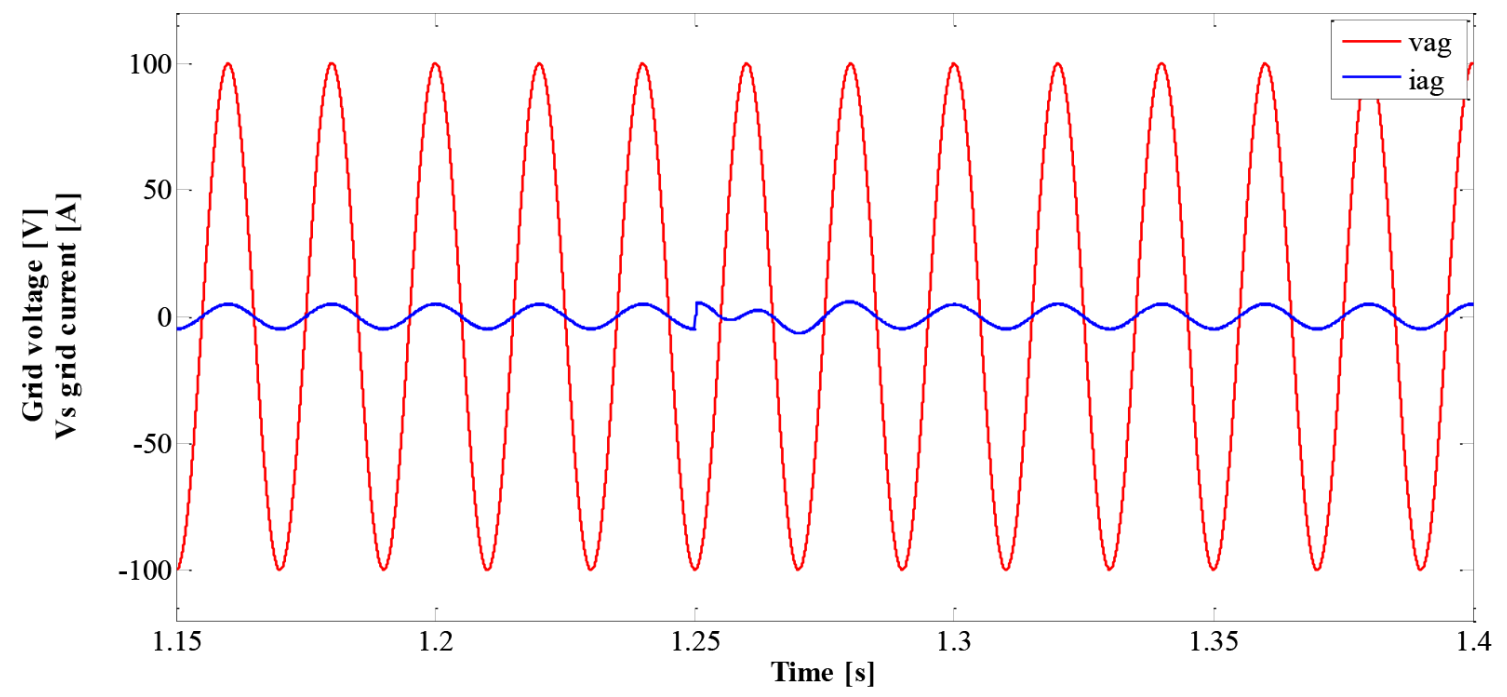

Fig. 13 Grid current and grid voltage 
As illustrates Figs. 14 to 16 the measured $d$ or $q$ currents are tracked their references precisely and in decoupled form that's mean we can control $d$ or $q$ separately.

\subsection{Experimental results and discussion}

\subsubsection{GSC results}

Figs. 17 to 19 show the dynamic response of the DC-link voltage. We can see with clarity the capacitor voltage kept their reference in mode permanent without static error. The dynamic response of the Dc-link voltage takes $20 \mathrm{~ms}$ to reach their reference. That result slow response of PI controller. But this controller allows the bidirectional power flow between the rotor of DFIG and electrical grid. In other side, when the DC-link voltage reference value change from $220 \mathrm{~V}$ to $250 \mathrm{~V}$ the active power and line current are increase. The grid voltage and grid current are in phase, that's mean the power factor is unity and obtained when the reactive power set to zero. It is verified that the current is practically sinusoidal. The great ripple in measured active and reactive power caused by a limited choice of the sampling time in experimental setup with $\mathrm{dSPACE} 1104 \operatorname{card}\left(T_{s}=90 \mu \mathrm{s}\right)$.

\subsubsection{RSC results}

Figs. 20 and 21 illustrates an experiment based on the change in the value of the current $i_{d r}{ }^{*}$, where we started by a positive value $4 \mathrm{~A}$ in the time domain [0-9 $\mathrm{s}]$, and then we reduced it to a negative value $-2 \mathrm{~A}$ in the time domain [1-2.6 s] and finally we returned it to a positive value $4.5 \mathrm{~A}$ in the period [2.6-3.6 s]. On the contrary, the value of the $i_{q r}{ }^{*}$

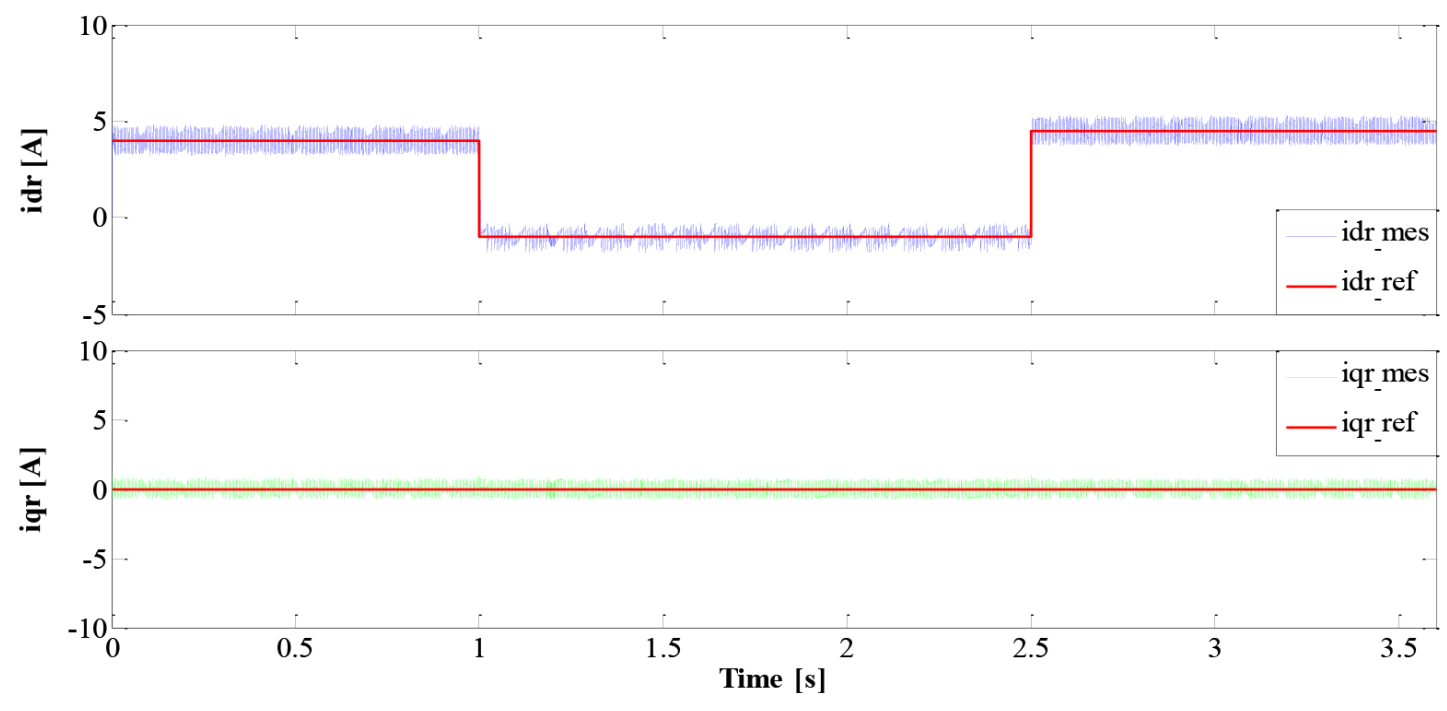

Fig. $14 i_{d r}$ varied and $i_{q r}$ fixe

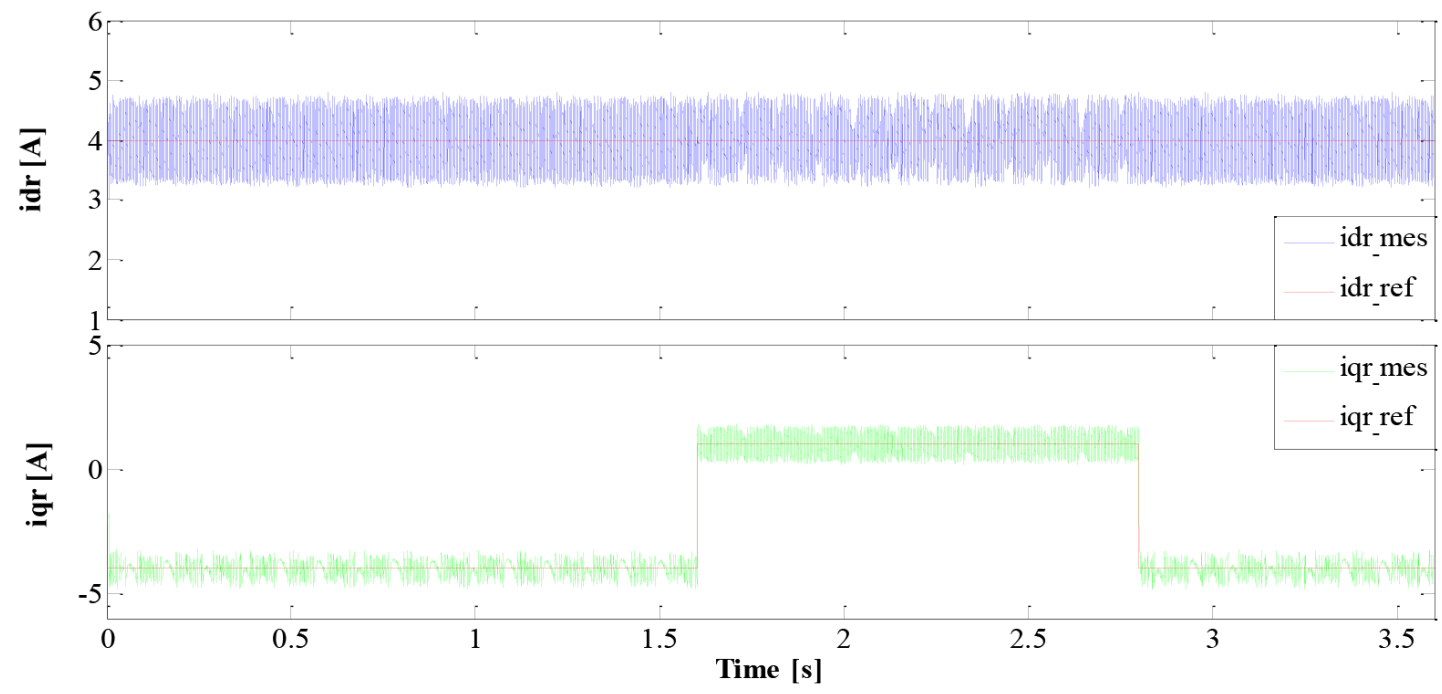

Fig. $15 i_{d r}$ fixed and $i_{q r}$ varied 


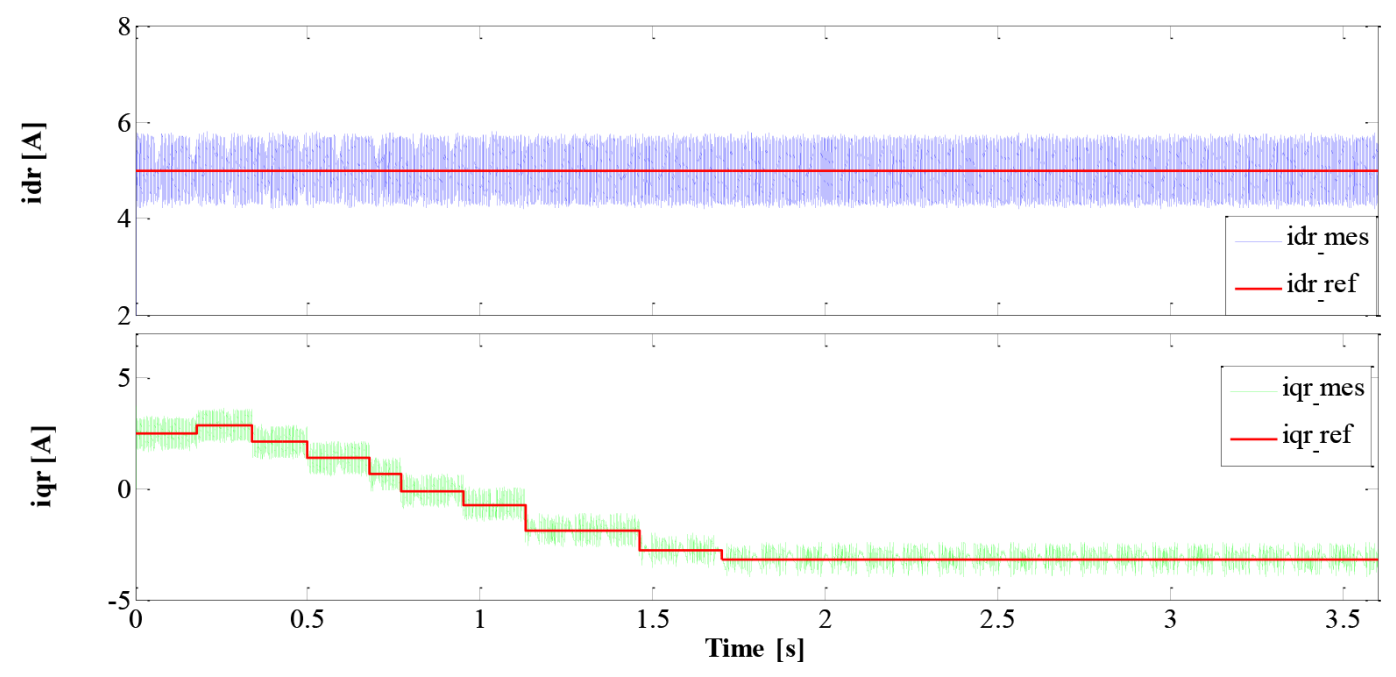

Fig. $16 i_{d r}$ varied and $i_{q r}$ fixe

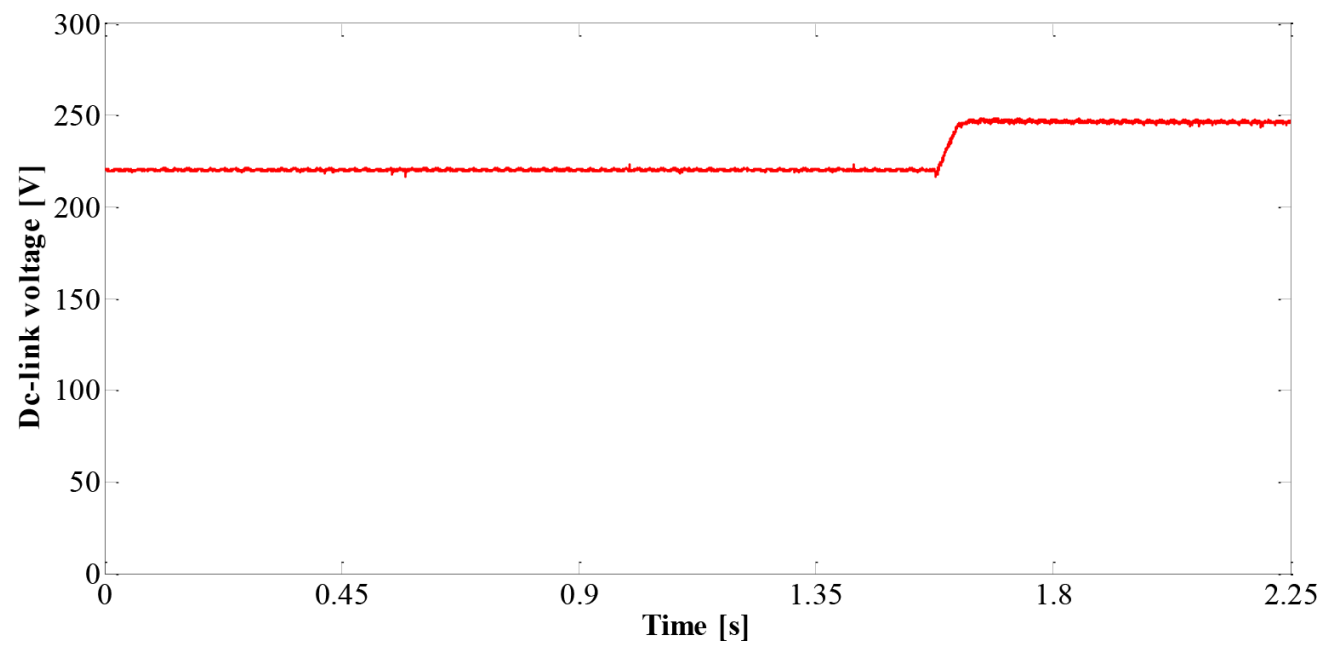

Fig. 17 DC-link voltage

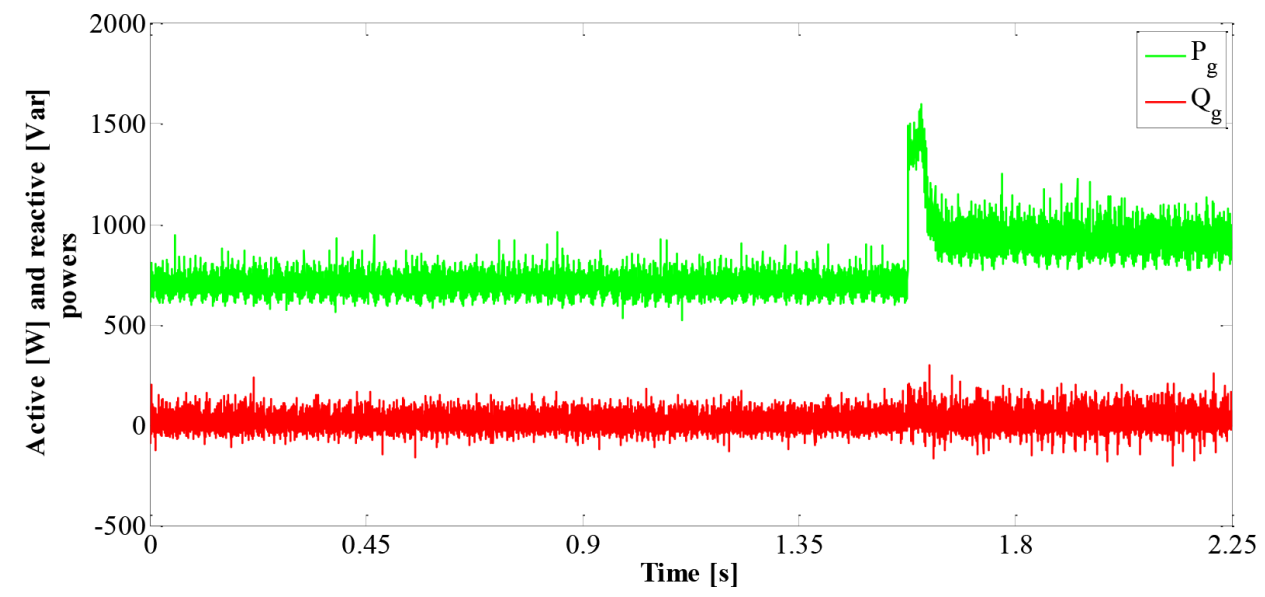

Fig. 18 Active and reactive power 


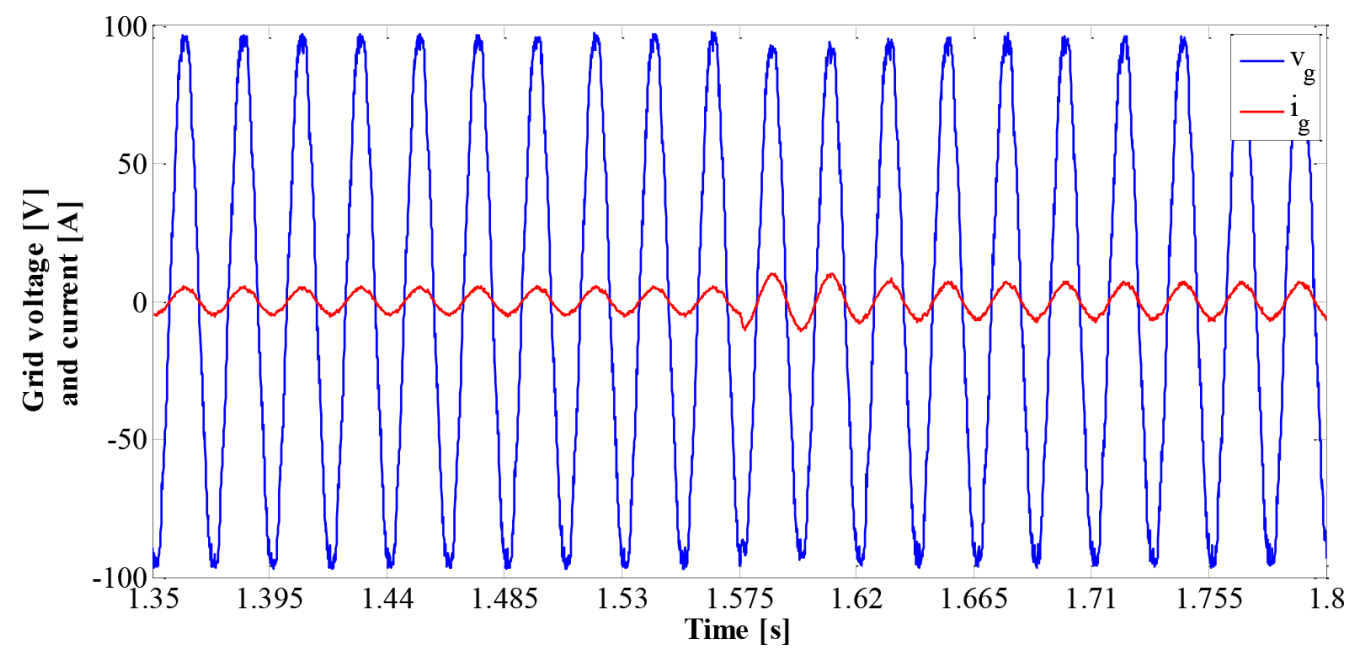

Fig. 19 Grid current and grid voltage

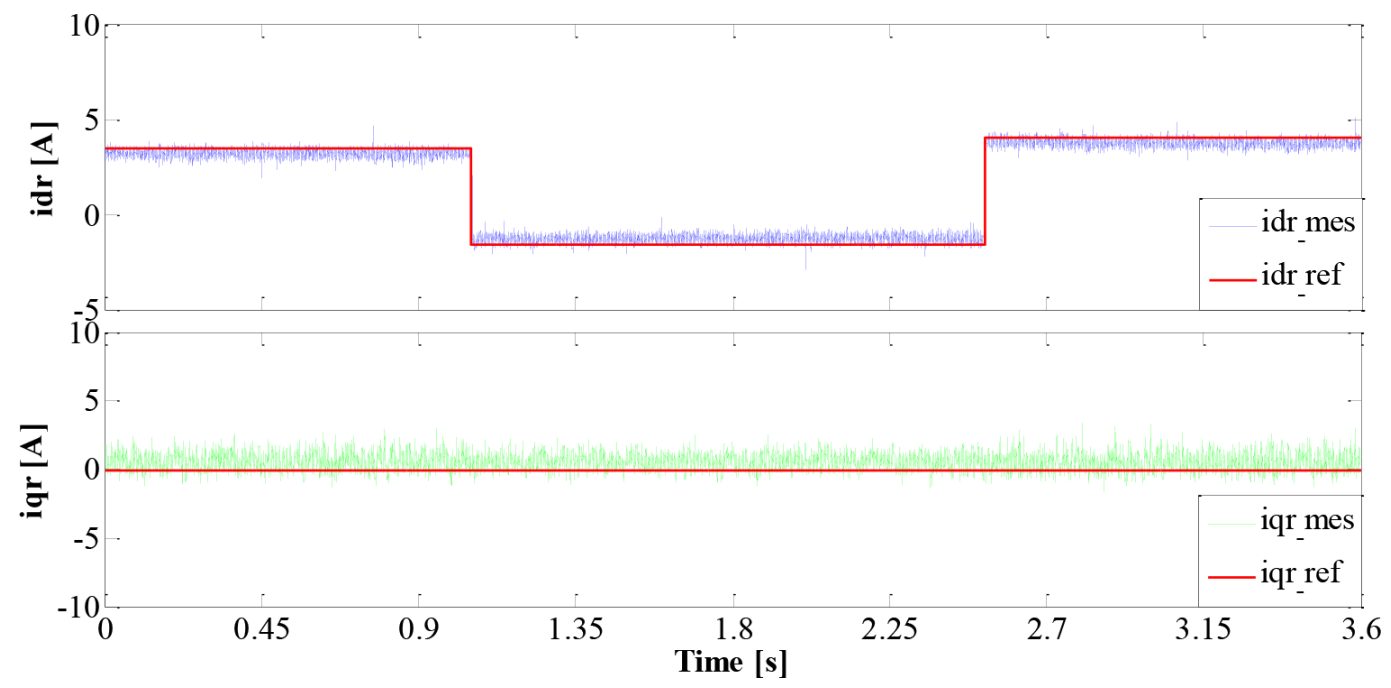

Fig. $20 i_{d r}$ varied and $i_{q r}$ fixe

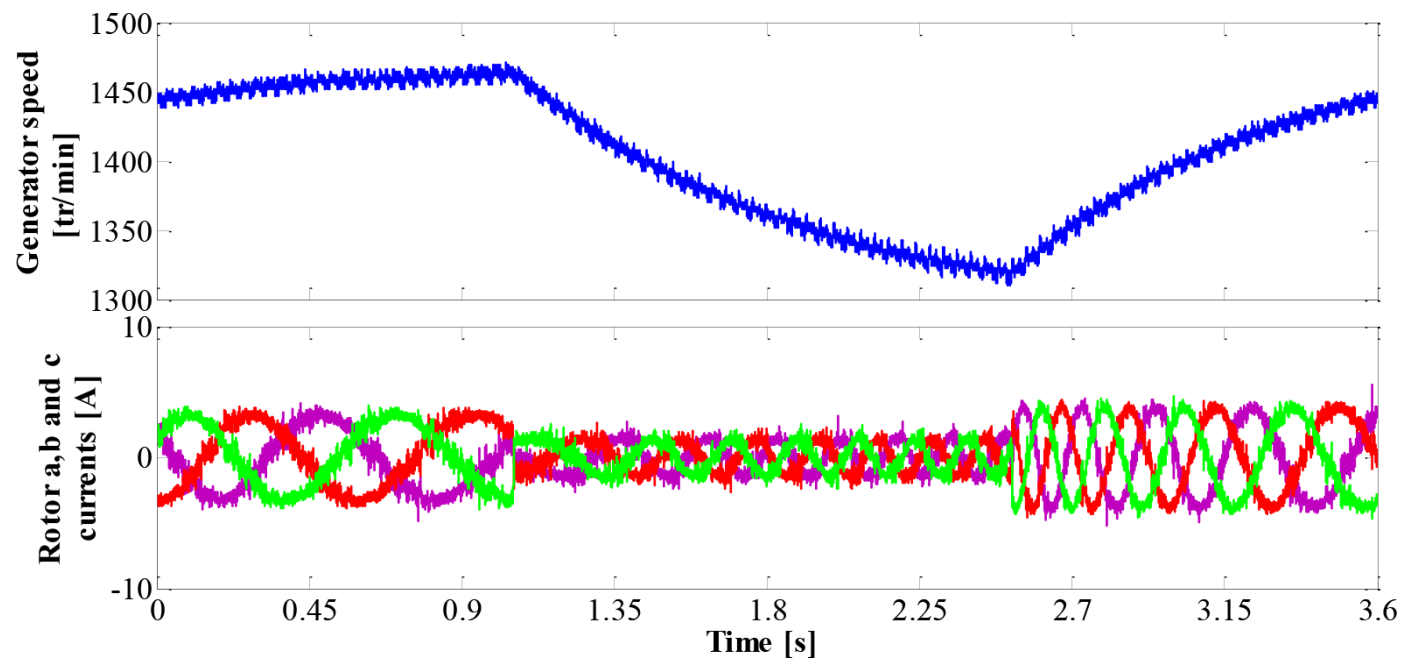

Fig. 21 Rotor currents and generator speed 
current remained constant 0 A during this test. Here we clearly notice that the change in the value of the $i_{d r}{ }^{*}$ current is followed by a change in the speed of the motor proportional to the change in the current where if the value of the current increases, the speed also increases and vice versa. Here, the DFIG functioning in mode hypo-synchronous (the speed of machine is less than to the synchronous speed $1500 \mathrm{tr} / \mathrm{min}$ ).

Figs. 22 and 23 presents the same tests in the previous figure but here we changed the value of the current $i_{q r}{ }^{*}$, where we started by $-4 \mathrm{~A}$ in $[0-1.6 \mathrm{~s}], 1 \mathrm{~A}$ in the [1.6-2.75 s] and finally $-4 \mathrm{~A}$ in the period [2.75-3.6 s]. The $i_{d r}{ }^{*}$ is take the fixe value in all test $+4 \mathrm{~A}$. Also, the change in the value of the current $i_{q r}{ }^{*}$ directly affects the value of the speed. Contrary to the first test the DFIG functioning in mode hyper-synchronous (the speed of machine is greater than to the synchronous speed $1500 \mathrm{tr} / \mathrm{min})$.
The Fig. 24 shows how the direction of the three-phase rotor current changes with the change in the value of the speed and this result when we change the value of the current $i_{q r}{ }^{*}$ from $2.5 \mathrm{~A}$ to $-2.5 \mathrm{~A}$. PCC performance is examined when varying the rotor speed from 1440 to $1640 \mathrm{tr} / \mathrm{min}$, as shown in Fig. 24. During the test, the rotor $d$-axis current is constant at $5 \mathrm{~A}$ but the $q$-axis current is varied from $2 \mathrm{~A}$ to $-2.5 \mathrm{~A}$. As seen, during the speed variation, the rotor and stator currents are well controlled. The rotor current frequency decreases initially due to the reduced rotor slip, reaching zero at the $1500-\mathrm{r} / \mathrm{min}$ synchronous speed, and increases after passing $1500 \mathrm{r} / \mathrm{min}$.

As we see in Figs. 20, 22 and 24 the tracking performance shows high dynamic performance for both $d-q$ axis rotor current since the $d-q$ axis are perfectly decoupled and track their references accurately and precisely.

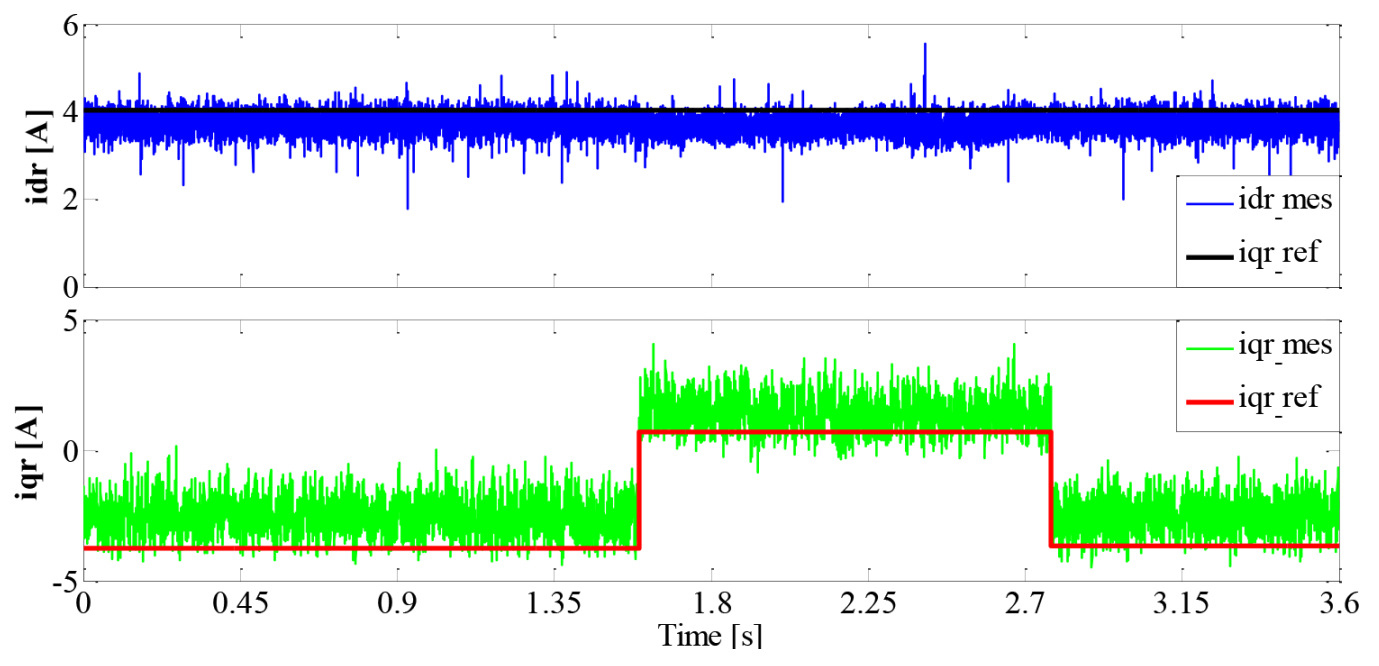

Fig. $22 i_{d r}$ fixe and $i_{q r}$ varied

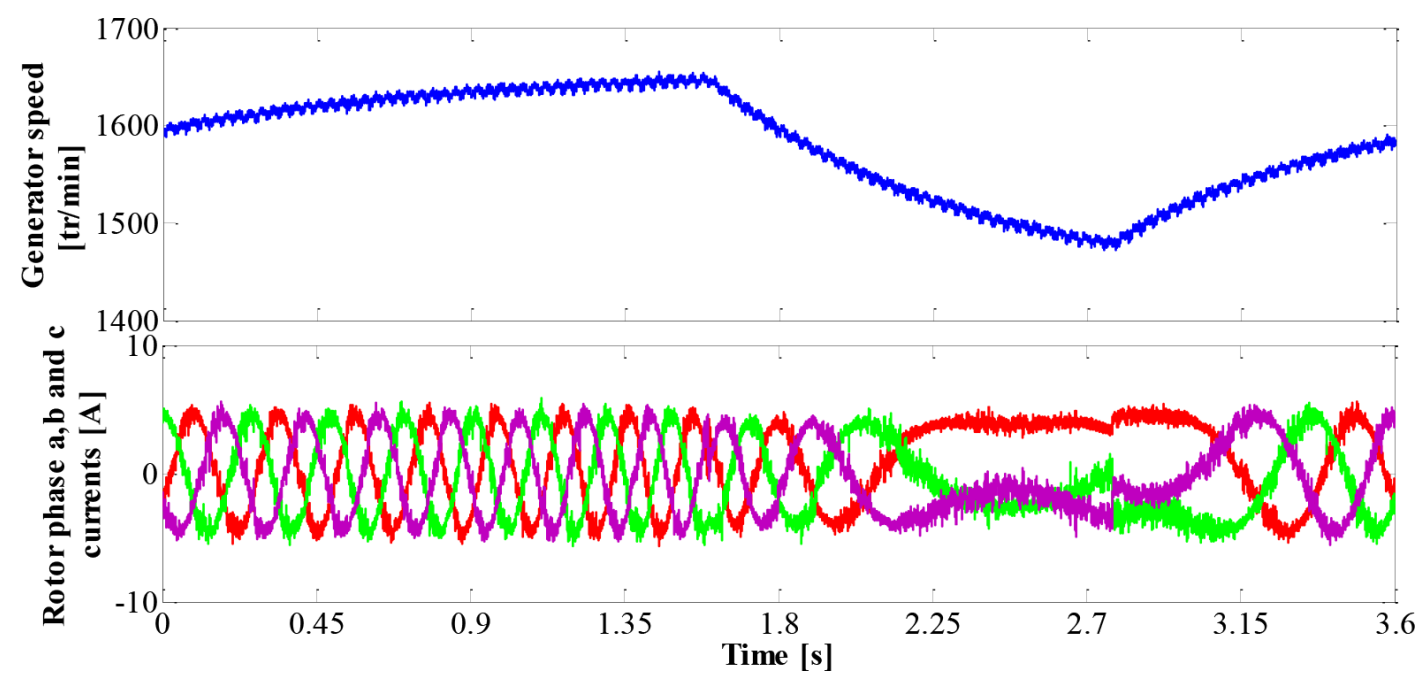

Fig. 23 Rotor currents and generator speed 
Figs. 21, 23 and 25 shows the rotor current and speed mechanics during a transition from hypo-synchronous regime to hyper-synchronous speed. These results confirm that the DFIG can operate in both regimes while allowing a smooth transition during the change of regime.
Fig. 26 shows the rotor current $i_{a r}$, the stator current $i_{a s}$ and the stator voltage $v_{a s}$. It is seen that the stator current and voltage are not in phase and not in opposite in phase because the value of a $i_{d r} \neq \frac{V_{s}}{w_{s} M}$. Furthermore, the rotor current operates with a low frequency along the wind speed

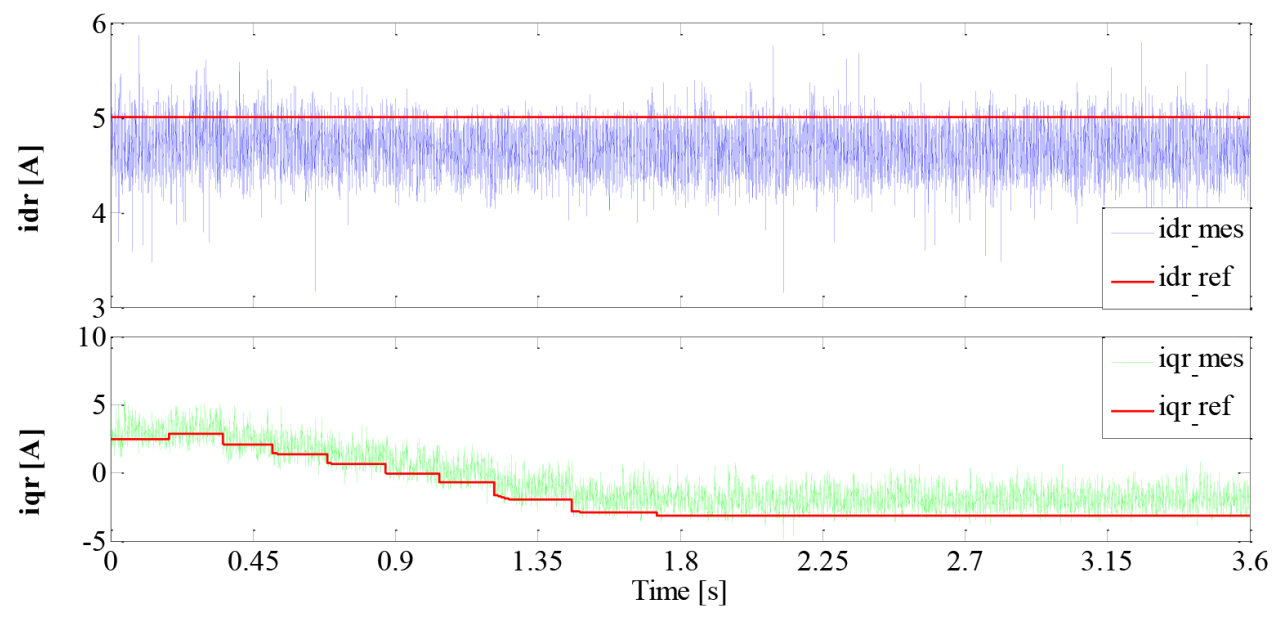

Fig. $24 i_{d r}$ varied and $i_{q r}$ fixe

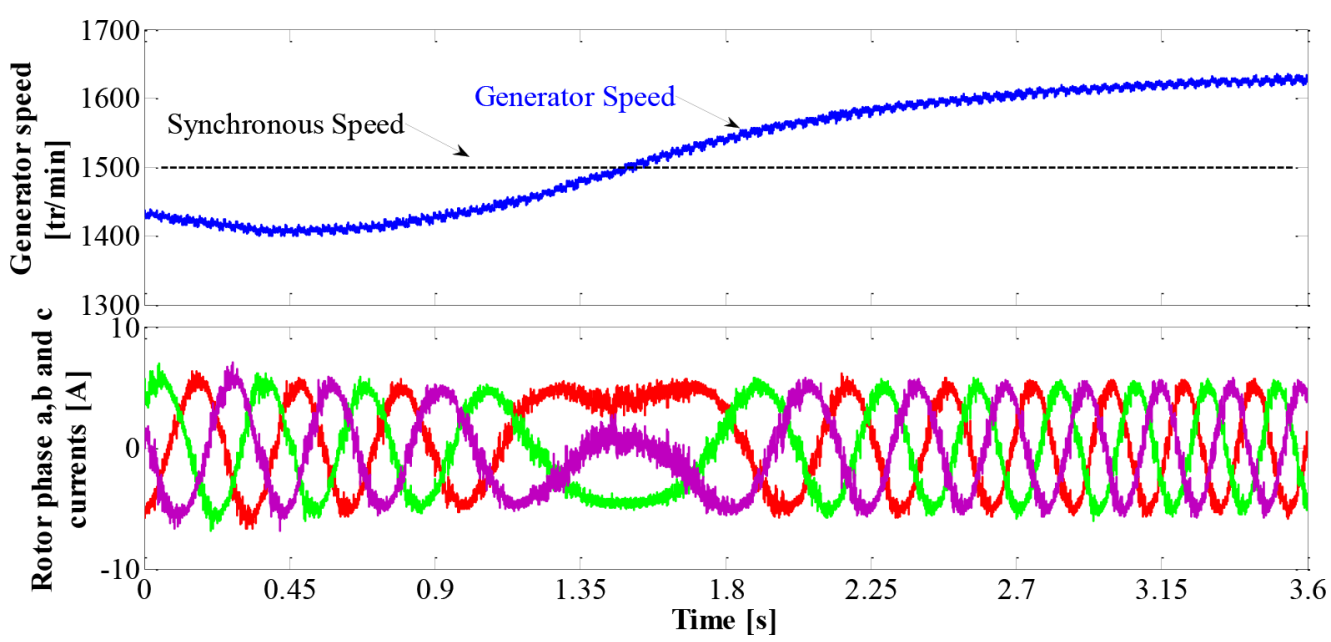

Fig. 25 Rotor currents and generator speed

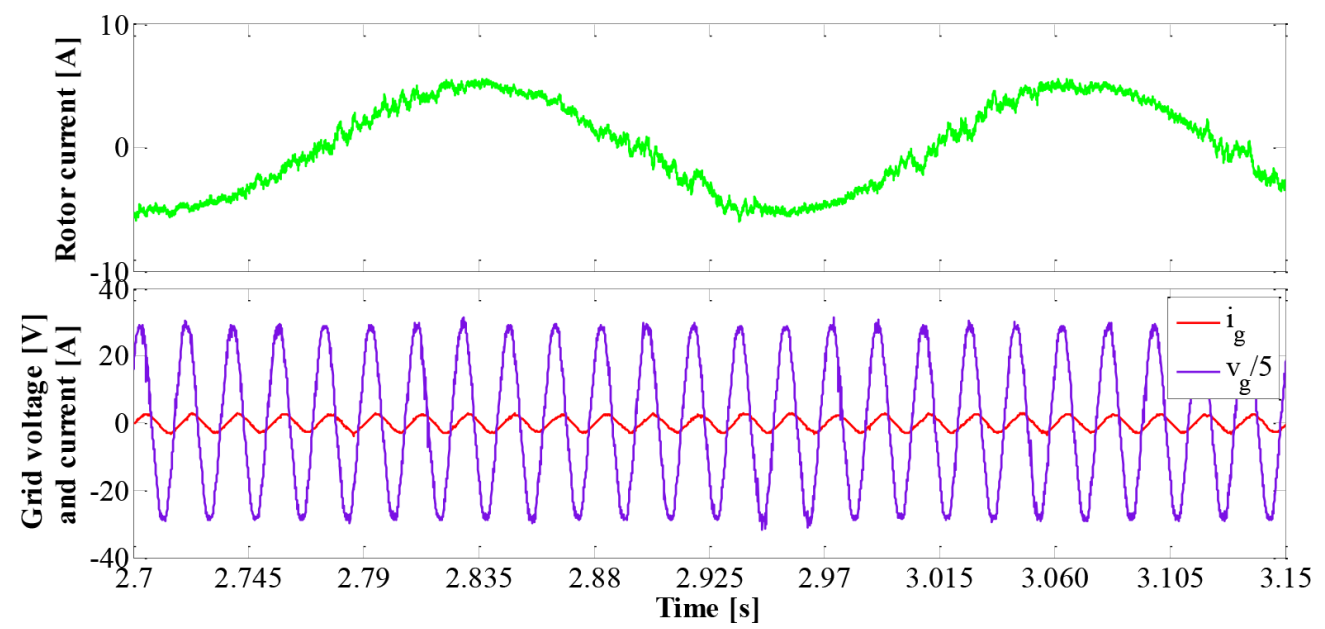

Fig. 26 (green) Phase (a) rotor current $\left(i_{a r}+30\right)$, (red) Phase (a) stator current, (blue) phase (a) stator voltage, $\left(v_{a s} / 10\right)$ 
profile and its amplitude is depending on the amplitude of the wind speed (where the value of the $i_{d r}$ or $i_{q r}$ increases or decreases the amplitude of the rotor current also increases or decreases, respectively). It should also be noted that the frequency of the rotor current is much lower compared to that of the stator current. Also, when the stator current is in phase opposition with the voltage, thus allowing the generator to deliver only active power to the network.

\section{Conclusions}

A direct predictive control strategy is proposed and applied to control a wind energy conversion chain based on a doubly fed induction generator using a tow level back-toback converter. The most advantage of the proposed control method is its simplicity in implementation, since the method avoids the use of linear or nonlinear controllers except for the external wind speed loop and there is no need for any type of modulator, such as in PWM modulation, which can reduce the overall cost of the drive system. The control scheme is very simple and uses discrete model of the converter to predict the behavior of rotor currents and to

\section{References}

[1] Global Wind Energy Council "Global Wind Report 2021", Global Wind Energy Council, Brussels, Belgium, 2021. [online] Available at: https://gwec.net/global-wind-report-2021 [10 March 2021]

[2] Tang, W., Hu, J., Chang, Y., Liu, F. "Modeling of DFIG-Based Wind Turbine for Power System Transient Response Analysis in Rotor Speed Control Timescale", IEEE Transactions on Power Systems, 33(6), pp. 6795-6805, 2018.

https://doi.org/10.1109/TPWRS.2018.2827402

[3] Dekali, Z., Baghli, L., Boumediene, A., Djemai, M. "Control of a Grid Connected DFIG Based Wind Turbine Emulator", In: 2018 5th International Symposium on Environment-Friendly Energies and Applications (EFEA), Rome, Italy, 2018, pp. 1-6. https://doi.org/10.1109/EFEA.2018.8617049

[4] Akel, F., Ghennam, T., Berkouk, E. M., Laour, M. "An improved sensorless decoupled power control scheme of grid connected variable speed wind turbine generator", Energy Conversion and Management, 78, pp. 584-594, 2014.

https://doi.org/10.1016/j.enconman.2013.11.015

[5] Taib, N., Metidji, B., Rekioua, T. "Performance and efficiency control enhancement of wind power generation system based on DFIG using three-level sparse matrix converter", International Journal of Electrical Power \& Energy Systems, 53, pp. 287-296, 2014. https://doi.org/10.1016/j.ijepes.2013.05.019

[6] Bevilaqua, M. A., Nied, A., de Oliveira, J. "Labview FPGA FOC implementation for synchronous Permanent Magnet Motor Speed Control", In: 2014 11th IEEE/IAS International Conference on Industry Applications, Juiz de Fora, Brazil, 2014, pp. 1-8. https://doi.org/10.1109/INDUSCON.2014.7059427 obtain the best suited converter switching state. Simulation results show accurate tracking performance with a significant reduction of oscillation of current that improves the efficiency of the conversion chain. The proposed controller algorithm is designed and implemented on experimental bench of a $3 \mathrm{KW}$-DFIG in a real time via a dSPACE 1104 card. The obtained results validate the control strategies, and provided a good dynamic performance in term the response time, robustness and dynamics accurate tracking.

\section{Acknowledgments}

The authors wish to thank the financial support from the university of L'Arbi Ben M'hidi of Oum El bouaghi Algeria. Also, I would like to express my sincere gratitude to my co supervisor Prof. Abdellatif Reama, professor at the Ecole d'ESIEE of Paris for the continuous support of my internship study and research, for his patience, motivation, enthusiasm, and immense knowledge. His guidance helped me in all the time of research. This experimental work is realized just in 90 days (the duration external internship in Ecole d'ESIEE Paris).

[7] Cardenas, R., Pena, R. "Sensorless vector control of induction machines for variable-speed wind energy applications", IEEE Transactions Energy Conversion, 19(1), pp. 196-205, 2004. https://doi.org/10.1109/TEC.2003.821863

[8] Lin, H., Yan, W., Li, M., Wen, P., Zhang, C., Li, M. "Direct torque control of an IPM synchronous motor drive using model reference adaptive backstepping approach", In: 2009 IEEE International Conference on Robotics and Biomimetics (ROBIO), Guilin, China, 2009, pp. 2119-2124.

https://doi.org/10.1109/ROBIO.2009.5420507

[9] Kowalski, C. T., Lis, J., Orlowska-Kowalska, T. "FPGA Implementation of DTC Control Method for the Induction Motor Drive", In: EUROCON 2007 - The International Conference on "Computer as a Tool", Warsaw, Poland, 2009, pp. 1916-1921. https://doi.org/10.1109/EURCON.2007.4400657

[10] Depenbrock, M. "Direct self-control (DSC) of inverter-fed induction machine", IEEE Transactions on Power Electronics 3(4), pp. $420-429$. https://doi.org/10.1109/63.17963

[11] Yaramasu, V., Wu, B. "Model Predictive Control of Wind Energy Conversion Systems", IEEE Press Series on Power Engineering, John Wiley \& Sons, New York, NY, USA, 2016.

[12] Vargas, R., Cortes, P., Ammann, U., Rodriguez, J., Pontt, J. "Predictive Control of a Three-Phase Neutral-Point-Clamped Inverter", IEEE Transactions on Industrial Electronics, 54(5), pp. 2697-2705, 2007.

https://doi.org/10.1109/TIE.2007.899854 
[13] Cortes, P., Rodriguez, J., Quevedo, D. E., Silva, C. "Predictive Current Control Strategy With Imposed Load Current Spectrum", IEEE Transactions on Power Electronics, 23(2), pp. 612-618, 2008. https://doi.org/10.1109/TPEL.2007.915605

[14] Ghennam, T., Berkouk, E. M. "Back-to-back three-level converter controlled by a novel space-vector hysteresis current control for wind conversion systems", Electric Power Systems Research, 80(4), pp. 444-455, 2010.

https://doi.org/10.1016/j.epsr.2009.10.009

[15] Verij Kazemi, M., Sadeghi Yazdankhah, A., Madadi Kojabadi, H. "Direct power control of DFIG based on discrete space vector modulation", Renewable Energy, 35(5), pp. 1033-1042, 2010. https://doi.org/10.1016/j.renene.2009.09.008

[16] Bouharchouche, A., Berkouk, E. M., Ghennam, T., Tabbache, B. "Modeling and control of a Doubly fed induction generator with battery-supercapacitor hybrid energy storage for wind power applications", In: 4th International Conference on Power Engineering, Energy and Electrical Drives, Istanbul, Turkey, 2013, pp. 1392-1397. https://doi.org/10.1109/PowerEng.2013.6635818

[17] Aimani, S. E. "Modelling and control structures for variable speed wind turbine", In: 2011 International Conference on Multimedia Computing and Systems, Ouarzazate, Morocco, 2011, pp. 1-5. https://doi.org/10.1109/ICMCS.2011.5945670

[18] Chikha, S., Barra, K. "Predictive Control of Variable Speed Wind Energy Conversion System with Multi Objective Criterions", Periodica Polytechnica Electrical Engineering and Computer Science, 60(2), pp. 96-106, 2016. https://doi.org/10.3311/PPee.8873

[19] Ghennam, T., Berkouk, E. M., Francois, B., Aliouane, K. "A New Space-Vector Based Hysteresis Current Control Applied on ThreeLevel Inverter to Control Active and Reactive Powers of Wind Generator", In: 2007 International Conference on Power Engineering, Energy and Electrical Drives, Setubal, Portugal, 2007, pp. 636-641. https://doi.org/10.1109/POWERENG.2007.4380108

[20] Barra, K., Rahem, D. "Predictive direct power control for photovoltaic grid connected system: An approach based on multilevel converters", Energy Conversion and Management, 78, pp. 825-834, 2014. https://doi.org/10.1016/j.enconman.2013.06.064

[21] Rodríguez, J., Pontt, J., Silva, C., Salgado, M., Rees, S., Ammann, U., Lezana, P., Huerta, R., Cortés, P. "Predictive control of threephase inverter", Electronics Letters, 40(9), pp. 561-563, 2004. https://doi.org/10.1049/el:20040367

[22] Perantzakis, G. S., Xepapas, F. H., Manias, S. N. "Efficient predictive current control technique for multilevel voltage source inverters", In: 2005 European Conference on Power Electronics and Applications, Dresden, Germany, 2005, Article number: 10. https://doi.org/10.1109/EPE.2005.219543
[23] Chikha, S., Barra, K., Reama, A. "Predictive current control of a wind energy conversion system based DFIG via direct matrix converter", In: IREC2015 The Sixth International Renewable Energy Congress, Sousse, Tunisia, 2015, pp. 1-7. https://doi.org/10.1109/IREC.2015.7110888

[24] Antoniewicz, P., Kazmierkowski, M. P. "Virtual-Flux-Based Predictive Direct Power Control of AC/DC Converters With Online Inductance Estimation", IEEE Transactions on Industrial Electronics, 55(12), pp. 4381-4390, 2008. https://doi.org/10.1109/TIE.2008.2007519

[25] Fan, B., Fu, Z., Michels, K. "Model predictive direct power control based on error correction for three-phase voltage source PWM rectifier", International Transactions on Electrical Energy Systems, 30(4), Article number: e12263, 2020.

https://doi.org/10.1002/2050-7038.12263

[26] Zaragoza, J., Pou, J., Arias, A., Spiteri, C., Robles, E., Ceballos, S. "Study and experimental verification of control tuning strategies in a variable speed wind energy conversion system", Renewable Energy, 36(5), pp. 1421-1430, 2011.

https://doi.org/10.1016/j.renene.2010.11.002

[27] Merahi, F., Berkouk, E. M., Mekhilef, S. "New management structure of active and reactive power of a large wind farm based on multilevel converter", Renewable Energy, 68, pp. 814-828, 2014. https://doi.org/10.1016/j.renene.2014.03.007

[28] Mesbahi, T., Ghennam, T., Berkouk, E. M. "A Doubly Fed Induction Generator for wind stand-alone power applications (Simulation and experimental validation)", In: 2012 XXth International Conference on Electrical Machines, Marseille, France, 2012, pp. 2028-2033. https://doi.org/10.1109/ICEIMach.2012.6350161

[29] Munteanu, I., Bratcu, A. I., Cutululis, N. A., Ceangă, E. "Optimal Control of Wind Energy Systems: Towards a Global Approach", Springer, London, UK, 2008. https://doi.org/10.1007/978-1-84800-080-3

[30] Munteanu, I., Bacha, S., Bratcu, A. I., Guiraud, J., Roye, D. "EnergyReliability Optimization of Wind Energy Conversion Systems by Sliding Mode Control", IEEE Transactions on Energy Conversion, 23(3), pp. 975-985, 2008. https://doi.org/10.1109/TEC.2008.917102

[31] Chandrasekaran, S., Rossi, C., Casadei, D., Tani, A. "Improved control strategy of wind turbine with DFIG for Low Voltage Ride Through capability", International Symposium on Power Electronics Power Electronics, Electrical Drives, Automation and Motion, Sorrento, Italy, 2012, pp. 19-24. https://doi.org/10.1109/SPEEDAM.2012.6264552

[32] Yao, J., Li, H., Liao, Y., Chen, Z. "An Improved Control Strategy of Limiting the DC-Link Voltage Fluctuation for a Doubly Fed Induction Wind Generator", IEEE Transactions on Power Electronics, 23(3), pp. 1205-1213, 2008. https://doi.org/10.1109/TPEL.2008.921177 


\section{Appendix}

Table 1 Wind turbine system parameters

\begin{tabular}{|c|c|c|}
\hline Variables & Description & Experimental value \\
\hline \multicolumn{3}{|l|}{ Source } \\
\hline$V_{s}$ & RMS supply grid voltage phase (V) & 220 \\
\hline$f_{s}$ & Supply Frequency (Hz) & 50 \\
\hline \multicolumn{3}{|l|}{ DFIG } \\
\hline$V_{s}$ & RMS supply stator voltage phase (V) & 220 \\
\hline$V_{r}$ & RMS supply rotor voltage phase (V) & 110 \\
\hline$P_{n}$ & Nominal power $(\mathrm{KW})$ & 3 \\
\hline$R_{r}$ & Rotor Resistance $(\Omega)$ & 1.7329 \\
\hline$R_{s}$ & Stator Resistance $(\mathrm{m} \Omega)$ & 88 \\
\hline$M$ & Mutual Inductance (mH) & 168.6 \\
\hline$L_{s}$ & Stator Inductance $(\mathrm{mH})$ & 175.2 \\
\hline$L_{r}$ & Rotor Inductance $(\mathrm{mH})$ & 175.2 \\
\hline$P$ & Number of pair of the pole & 2 \\
\hline \multicolumn{3}{|l|}{ DC-banc } \\
\hline$C$ & DC-link capacitance (uf) & 2200 \\
\hline$V_{d c}$ & Dc-link voltage (V) & 250 \\
\hline \multicolumn{3}{|l|}{ Grid } \\
\hline$L_{g}$ & Grid inductor $(\mathrm{mH})$ & 32 \\
\hline$R_{g}$ & Grid resistor $(\Omega)$ & 2.8 \\
\hline
\end{tabular}

